$T \mathrm{TD}-4500, \mathrm{UC}-34$

Physics

\author{
Lawrenoe Iandiation Inbomatory \\ UNIVEÁSITY OF CHIFORHIA \\ IIVERUORE
}

UCRL-51031

\title{
SENSITIVITY OF MONTE CARLO CAECULATIONS TO THE NEUTRON CROSS SECTIONS FOR NEUTRON TRANSPORT IN NITROGEN AND IN AIR
}

\author{
Luisa F. Hansen \\ John D. Anderson \\ John L. Kammerdiener \\ Calvin Wong \\ MS date: March 22, 1971
}

\begin{abstract}
Thib report was brepired is in eccount of woek zponsored by the Ualted States Government. Neither the United Stutes nor the United States Alomic Enerty Commlation, nor any of their employees, chor any of their cantractors, cubeontractors, or their employees, makes any warranty, express or inplied, or awmes any makes any wartansy, espress or lnplisd, or antumes any legal tisbility or responsibility for the accuracy, compieteness or usefolnt of any informition, epperatus, prodact of proctes diceloued, or represents thet th wes would not infringe privitely owsed rights.
\end{abstract}




\section{Contents}

\begin{tabular}{|c|c|c|c|c|c|c|c|c|c|c|c|c|c|c|c|c|}
\hline Abstract & - & * & & - & - & - & - & & & • & - & & & - & - & • \\
\hline Introduction & - & & & - & & - & - & & & - & - & & & • & - & - \\
\hline Oxygen Cross Sec & tions & . & & - & & - & - & & & - & - & & & - & $\cdot$ & . \\
\hline Nitrogen Cross S & ections & re & • & - & & - & - & & & - & - & & & - & • & - \\
\hline $\begin{array}{l}\text { Comparison of the } \\
\text { With Other Eva }\end{array}$ & $\begin{array}{l}\text { e Calc } \\
\text { luatior }\end{array}$ & & • & in & & . & . & & & & . & & & . & * & - \\
\hline Conclusions & - & . & . & - & & - & - & & & - & - & & & . & - & . \\
\hline Aclnowledgment & - & & & - & & - & - & & & - & - & & & - & . & $=$ \\
\hline References & - & & • & - & - & - & - & & & - & - & & & - & - & . \\
\hline
\end{tabular}




\title{
SENSITIVITY OF MONTE CARLO CALCULATIONS TO THE NEUTRON CROSS SECTIONS FOR NEUTRON TRANSPORT IN NITROGEN AND IN AIR
}

\begin{abstract}
The predictions of the SORS Monte Carlo calculations for neutron transport from a 14-MeV neutron source in nitrogen and in air are compared using different libraries for nitrogen. In turn, these libraries are tested against experimental measurements for the integral neutron spectra betweer: 0.5 and $10 \mathrm{mfp}$ at $14 \mathrm{MeV}$. The measured neutron spectra cover a neutron energy range between $1 \mathrm{eV}$ and $14 \mathrm{MeV}$. The neutron library for oxygen is checked against measurements for $0.72 \mathrm{mfp}$ at $14 \mathrm{MeV}$ for neutron energies between $30 \mathrm{keV}$ and $14 \mathrm{MeV}$.

It is found that features of neutron transport at $14 \mathrm{MeV}$ are mainly determined by the neutron cross sections at neutron energies close to the source energy. This is especially so for neutron dose as a function of distance from the source. Neutron Iuence as a function of neutron energy at a given distance from the source is, however, more sensitive to the neutron cross sections at energies below $14 \mathrm{MeV}$. This sensitivity is most pronounced at great distances from the neutron source.
\end{abstract}

\section{Introduction}

Numerous calculations are found in the literature on the problem of neutron transport in air. ${ }^{1}$ For example, very extensive and complete calculations have been carried out by Straker, 2,3 who has compared them with some of the wellknown and more comprehensive ones. The authors of this paper have performed similar calculations, ${ }^{4}$ and these have been compared with Straker's ${ }^{3}$ results. The neutron transport caiculations presented in Ref. 4 used the neutron cross sections for nitrogen and oxygen, which had been previously tested against the integral measurements for $0.58,1.06$, and $3.0 \mathrm{mfp}$ of nitrogen and $0.72 \mathrm{mfp}$ oxygen. It was shown ${ }^{4}$ that the proper treatment of inelastic neutron scattering

\footnotetext{
The results presented in this paper were reported at the Seventeenth Annual Meeting of the American Nuclear Society (June 1970).
} 
to discrete levels was necessary for the calculations to reproduce the measurements. Furthermore, it has been found that the neutron transport calculations of dose as a function of distance from the source are sensitive mainly to the neutron cross sections for the higher-energyr neutrons.

\section{Oxygen Cross Sections}

For oxygen the cross sections at

$14 \mathrm{MeV}$ used in the calculations ${ }^{4}$ pere as follows: $\sigma_{\text {total }}=1678$ moar,

$\sigma_{e 1}=880$ mbar, $\sigma_{n-e l}=798 \mathrm{mbar}$, $\sigma\left(n, n^{\prime}\right)=463$ mbar, $\sigma(n, p)=50$ mbar and $\sigma(n, \alpha)=285$ mbar. As described in detail in Ref. 4, five inelastic levels were considered: a level at $6.10 \mathrm{MeV}$ to account for the doublet at 6.05 and $6.13 \mathrm{MeV}$; a level at $7.00 \mathrm{MeV}$ to account for the doublet at 6.92 and $7.12 \mathrm{MeV}$; 2 level at $8.88 \mathrm{MeV}$; a level at $9.90 \mathrm{MeV}$ to represent the triplet at $9.59,9.85$, and 10.36 MeV; and a level at $11.10 \mathrm{MeV}$ to account for the triplet at 10.95, 11.08, and $11.26 \mathrm{MeV}$. The cross section assigned to these five levels was $182 \mathrm{mbar}$ distributed according to the ratio 0.593 ,

Table 1. Neutron library for oxygen

\begin{tabular}{|c|c|c|c|c|c|c|c|c|c|c|}
\hline Group & $\underset{\text { (Mitlal }}{E_{\text {(rit) }}}$ & $\underset{\text { (MeV) }}{\mathrm{E}_{\mathrm{av}}}$ & $\begin{array}{c}\sigma_{\text {total }} \\
\text { (mbat) }\end{array}$ & $\begin{array}{l}\text { Oelastic } \\
\text { (mbar) }\end{array}$ & $\begin{array}{c}\sigma_{n-e} \\
(m b a r)\end{array}$ & $\begin{array}{l}\text { o(n,n') } \\
\text { levels } \\
\text { (mbar) }\end{array}$ & $\begin{array}{c}\sigma_{\left(n, n^{\prime}\right)} \\
\text { cont inuum } \\
\text { (mbar) }\end{array}$ & ${ }_{(m, 2 n)}^{0}$ & $\sigma_{\left(m, x_{2}\right)^{3}}$ & $\begin{array}{l}\sigma_{\left(n, x_{2}\right)} \\
\text { (mbar) }\end{array}$ \\
\hline $\begin{array}{l}\mathbf{3 2} \\
\mathbf{3 3} \\
\mathbf{3 4} \\
\mathbf{7 5} \\
\mathbf{3 6}\end{array}$ & $\begin{array}{l}1.602 \\
1.791 \\
1.989 \\
2.198 \\
2.418\end{array}$ & $\begin{array}{l}1.696 \\
1.880 \\
2.094 \\
2.308 \\
2.533\end{array}$ & $\begin{array}{r}1859 \\
2121 \\
1428 \\
845 \\
1118\end{array}$ & $\begin{array}{r}1859 \\
2121 \\
1428 \\
845 \\
1118\end{array}$ & $\begin{array}{l}- \\
- \\
-\end{array}$ & $\vec{u}-$ & $\underline{-}$ & $\begin{array}{l}- \\
- \\
-\end{array}$ & - & $\frac{-}{-}$ \\
\hline $\begin{array}{l}37 \\
38 \\
39 \\
40 \\
41\end{array}$ & $\begin{array}{l}2.648 \\
2.889 \\
3.140 \\
3.401 \\
3.673\end{array}$ & $\begin{array}{l}2.768 \\
3.014 \\
3.270 \\
3.537 \\
3.814\end{array}$ & $\begin{array}{l}1293 \\
1466 \\
2687 \\
3258 \\
3006\end{array}$ & $\begin{array}{l}1293 \\
1466 \\
2687 \\
3258 \\
2996\end{array}$ & $\overline{-}$ & $\underline{-}$ & $\underline{-}$ & $\begin{array}{c}- \\
- \\
-\end{array}$ & $\frac{-}{E}$ & $\frac{-}{10}$ \\
\hline $\begin{array}{l}42 \\
43 \\
44 \\
45 \\
48\end{array}$ & $\begin{array}{l}3.455 \\
4.248 \\
4.551 \\
4.865 \\
5.189\end{array}$ & $\begin{array}{l}\mathbf{4 . 1 0 2} \\
\mathbf{4 . 1 0 0} \\
\mathbf{4 . 7 0 8} \\
5.027 \\
5.356\end{array}$ & $\begin{array}{l}1695 \\
2191 \\
1525 \\
1848 \\
1087\end{array}$ & $\begin{array}{l}1607 \\
2134 \\
1470 \\
1740 \\
1076\end{array}$ & $\begin{array}{r}88 \\
57 \\
55 \\
108 \\
11\end{array}$ & $\vec{w}+$ & $\underline{-}$ & $\begin{array}{l}- \\
- \\
-\end{array}$ & $\frac{-}{-}$ & $\begin{array}{r}88 \\
57 \\
55 \\
108 \\
1 !\end{array}$ \\
\hline $\begin{array}{l}47 \\
48 \\
49 \\
50 \\
51\end{array}$ & $\begin{array}{l}5.524 \\
5.869 \\
6.224 \\
6.590 \\
6.957\end{array}$ & $\begin{array}{l}5.696 \\
6.016 \\
6.407 \\
6.778 \\
7.160\end{array}$ & $\begin{array}{r}1403 \\
1262 \\
957 \\
1055 \\
1245\end{array}$ & $\begin{array}{r}1390 \\
1223 \\
841 \\
904 \\
1027\end{array}$ & $\begin{array}{r}13 \\
39 \\
116 \\
151 \\
218\end{array}$ & $\begin{array}{r}- \\
1 \\
46 \\
93\end{array}$ & $\frac{-}{m}$ & $\begin{array}{c}- \\
- \\
-\end{array}$ & $\begin{array}{l}- \\
- \\
-\end{array}$ & $\begin{array}{r}13 \\
39 \\
115 \\
105 \\
125\end{array}$ \\
\hline $\begin{array}{l}\mathbf{5 2} \\
\mathbf{5 3} \\
\mathbf{5 4} \\
\mathbf{5 5} \\
\mathbf{5 6}\end{array}$ & $\begin{array}{l}7.354 \\
7.751 \\
8.159 \\
8.577 \\
9.006\end{array}$ & $\begin{array}{l}7.552 \\
7.955 \\
8.368 \\
6.792 \\
9.226\end{array}$ & $\begin{array}{l}1208 \\
1072 \\
125 i \\
1222 \\
1168\end{array}$ & $\begin{array}{l}931 \\
800 \\
851 \\
818 \\
730\end{array}$ & $\begin{array}{l}277 \\
272 \\
380 \\
404 \\
438\end{array}$ & $\begin{array}{l}195 \\
205 \\
325 \\
329 \\
330\end{array}$ & $\underline{-}$ & $\overline{-}$ & $\begin{array}{c}- \\
- \\
-\end{array}$ & $\begin{array}{r}82 \\
67 \\
55 \\
75 \\
108\end{array}$ \\
\hline $\begin{array}{l}57 \\
58 \\
59 \\
60 \\
61\end{array}$ & $\begin{array}{c}9.445 \\
9.894 \\
10.35 \\
10.83 \\
11.31\end{array}$ & $\begin{array}{c}9.670 \\
10.12 \\
10.59 \\
11.67 \\
11.55\end{array}$ & $\begin{array}{l}1298 \\
1358 \\
1282 \\
1563 \\
1684\end{array}$ & $\begin{array}{l}826 \\
810 \\
650 \\
891 \\
510\end{array}$ & $\begin{array}{l}472 \\
548 \\
642 \\
572 \\
774\end{array}$ & $\begin{array}{l}295 \\
335 \\
390 \\
390 \\
390\end{array}$ & $\begin{array}{r}45 \\
60 \\
80 \\
100 \\
140\end{array}$ & $\begin{array}{c}- \\
- \\
-\end{array}$ & $\begin{array}{r}- \\
1 \\
10 \\
52\end{array}$ & $\begin{array}{l}132 \\
152 \\
169 \\
179 \\
192\end{array}$ \\
\hline $\begin{array}{l}62 \\
63 \\
64 \\
65 \\
66\end{array}$ & $\begin{array}{l}11.80 \\
12.56 \\
13.33 \\
13.87 \\
14.41\end{array}$ & $\begin{array}{l}12.18 \\
12.94 \\
13.50 \\
14.14 \\
14.50\end{array}$ & $\begin{array}{l}1655 \\
1611 \\
1600 \\
1659 \\
1678\end{array}$ & $\begin{array}{l}860 \\
818 \\
795 \\
880 \\
880\end{array}$ & $\begin{array}{l}795 \\
793 \\
805 \\
779 \\
798\end{array}$ & $\begin{array}{l}390 \\
372 \\
290 \\
239 \\
182\end{array}$ & $\begin{array}{l}180 \\
210 \\
240 \\
241 \\
281\end{array}$ & $\frac{-}{-}$ & $\begin{array}{l}60 \\
45 \\
60 \\
59 \\
50\end{array}$ & $\begin{array}{l}165 \\
166 \\
215 \\
24 n \\
285\end{array}$ \\
\hline
\end{tabular}

${ }^{a} x_{1}$ and $x_{2}$ stand for single- and double-charged particles, respectively. 
$0.361,0.045,0.00 n$, and 0.001 , respectively. The $\left(n, n^{\prime}\right)$ cross section to the continuum accounts for 281 mbar. The tabulation of the oxygen cross sections between 1.6 and $14.5 \mathrm{MeV}$ is given in Tabie 1; the distribution of the (n,n') cross sections assigned to the inelastic levels as a function of the neutron energy is given in Table 2. For energies below 1.6 MEV, the neutron cross sections were taken from the LRL Neutron Library. ${ }^{6}$

Comparisons between the calculations (carried out with the computer prograri SORS ${ }^{7}$ using the above cross sections) and the measurements of the integral nsutron spectr $¥$ for reutron energies above $1.6 \mathrm{MeV}$ ana below $1 \mathrm{MeV}$ are displayed in Figs. 1 and 2, respectively.

Table 2. Probable distribution of the $\left(n, n^{\prime}\right)$ cross sections assigned to the levels as function of energy.

\begin{tabular}{|c|c|c|c|c|c|}
\hline \multirow{2}{*}{$\begin{array}{c}E_{1 a b} \\
(\mathrm{MeV})\end{array}$} & \multicolumn{5}{|c|}{$\begin{array}{c}\text { Excited levels for oxggen included in SORS } \\
\text { (MeV) }\end{array}$} \\
\hline & 6.10 & 7.00 & 8.88 & 9.90 & 11.1 \\
\hline 6.48 & 1 & -- & - & - & - \\
\hline 7.44 & 1 & - & - & - & - \\
\hline 8.00 & 0.885 & 0.115 & - & - & - \\
\hline 9.435 & 0.781 & 0.219 & - & - & - \\
\hline 10.52 & 0.586 & 0.329 & 0.085 & - & - \\
\hline 11.79 & 0.423 & 0.393 & 0.284 & - & - \\
\hline 12.0 & 0.406 & 0.393 & 0.198 & - & 0.003 \\
\hline 14.0 & 0.437 & 0.357 & 0.183 & - & 0.023 \\
\hline 16.0 & 0.593 & 0.361 & 0.045 & - & 0.001 \\
\hline
\end{tabular}

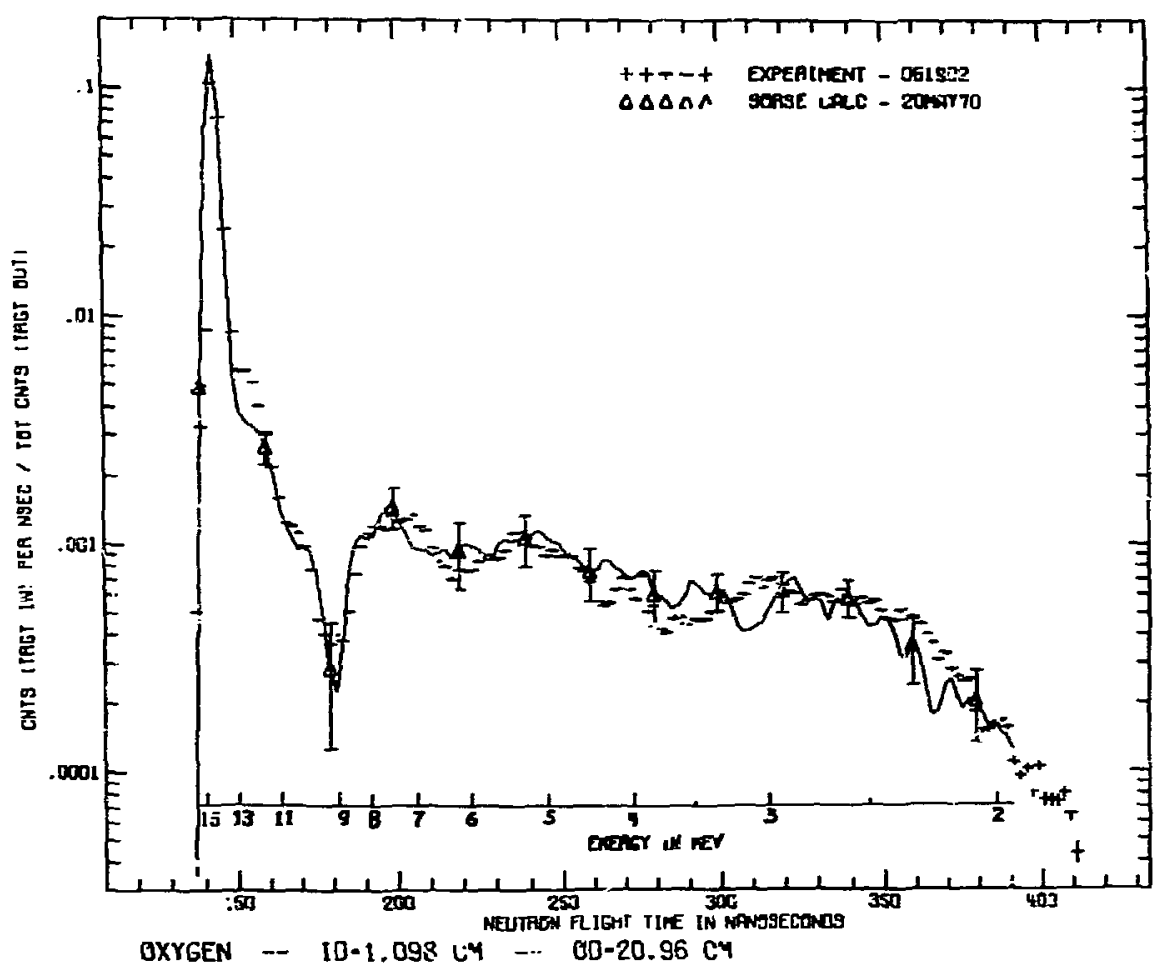

Fig. 1. Comparison between the measured neutron spectrum from $0.72 \mathrm{mfp}$ of liquid oxygen and the predictions of the SORS calculations with the cross sections given in Tables 1 and 2. 


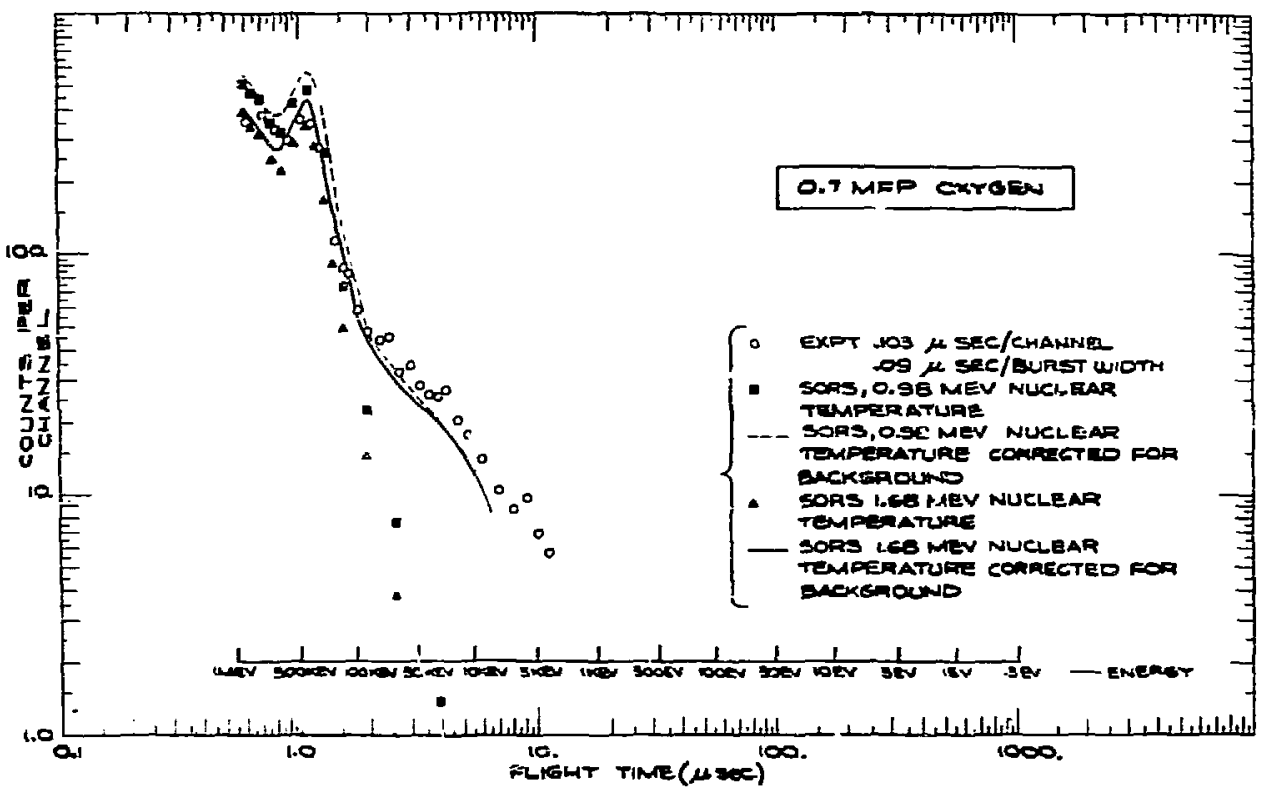

Fig. 2. Comparison between the measured neutron spectrum below $1 \mathrm{MeV}$ from $0.72 \mathrm{mip}$ of liquid oxygen and the SORS calculations carried out of two nuclear temperatures: $0.98 \mathrm{MeV}$ and $1.68 \mathrm{MeV}$.

For the low energy measurements ${ }^{5}$

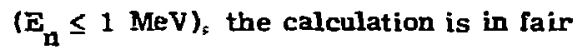
agreement down to $30 \mathrm{keV}$; below this energy the background corrections become very important and are rot too well known.

\section{Nitrogen Cross Sections}

For nitrogen, SORS calculations were carried out for two different neutron libraries, $A$ and $B$, which resulted ${ }^{4}$ from ihe inpassibility of reconciiing the total cross sections $^{8}$ with the sum of the elastic ${ }^{9}$ and nonelastic ${ }^{10}$ cross sections. It should be pointed out that Libraries $A$ and $B$ resulted from two extreme assumptions: in $A$ it was assumed that the measured elastic cross sections were too low, and they were raised accordingly to give the measured values of the total cross sections ${ }^{8}$; for $B$ the assumption was made that the measured ineizstic cross sections ${ }^{10}$ were too low, and consequently they were increased to agree with the values of $\sigma_{\text {total }}{ }^{8}$ The SORS calculations ${ }^{4}$ with Libraries $A$ and $B$ are compared with the measurements for $0.58,1.06$, and $3.0 \mathrm{~m}$ p of liquid nitrogen is Fig. 3. Libraries $A$ and $B$ are tabulated in Tableg 3 and 4, respectively. For neutron energies below $1.6 \mathrm{MeV}$, the neutron cross sections were again obtained from the LRL. Neutron Library. ${ }^{5}$ The main feafures of these two libraries are: (a) they 

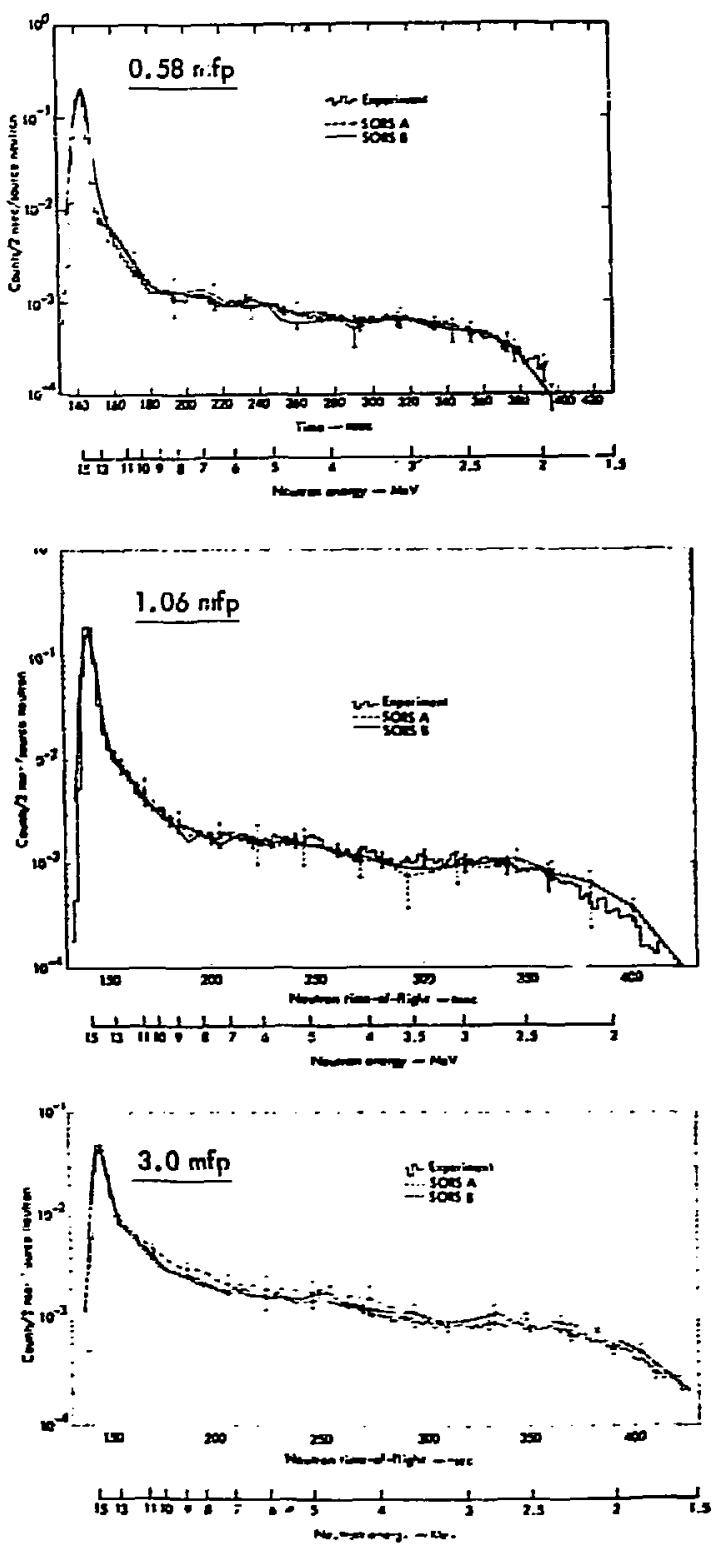

Fig. 3. Comparison between the measured neutron spectra from $0.58,1.06$, and $3.0 \mathrm{mfp}$ of liquid nitrogen and SóRS calculations carried out with neutron Libraries $A$ and $B$, given in Tables 3 and 4. have the same total cross section ${ }^{8}$; (b) discrepancies as large as 20 to $30 \%$ occur for the elautic cross sections and the nonelastic cross sections around 7-MeV neutron energy:and (c) the partial cross sections at $14 \mathrm{MeV}$ (group 66) are very similar. The differences between them are no la: er than the quoted $10 \%$ errors in the measurements. This last feature of the $14-\mathrm{MeV}$ cross sections is responsible for the close agreement between the two SORS calenlations with $\mathrm{i} i-$ braries $A$ and $B$. In spite of the closeness of these two calculations, Library $B$ seems to give sligin:- better overall agreement, particularly with the $3 \mathrm{mfp}$ measurements shown in Fig. 3.

These two libraries were also used by Sauter and Robinson ${ }^{11}$ to calculate the neutron transport through licisid ntrogen, where the $14-\mathrm{MeV}(\mathrm{d}, \mathrm{t})$ source and neutsea detector were both immersed in the nitrogen. These SORS calculations were compered with the measurements carried out by Gulf General Atomic (GGA). ${ }^{12,13}$ The calculations carried out with Libraries A and $B$ were normalized to the measurements. Figure 4, taken from Sauter and Robinson's ${ }^{11}$ report, compares the SORS predictions with the measurements at a distance of $195.8 \mathrm{~cm}$ (approximately $10 \mathrm{mfp}$ ) from the neutron source. The numbers in parentheses are the normalization factors. The shapes of the detector-output pulse height spectra obtained with these two calculations as a function of the sourcedetector distance are quite similar. particlilarly at the smaller distances. The need for normalization factors of the order of $50 \%$ or less at all distances is probably indicative of the source strength uncertainties in the GGA measurements. 
Table 3. Neutron Libráy A for nitrogen.

\begin{tabular}{|c|c|c|c|c|c|c|c|c|c|}
\hline Group & $\begin{array}{l}E_{\text {initial }} \\
\text { (Miev) }\end{array}$ & $\begin{array}{c}\sigma_{\text {total }} \\
\{\text { mbar\} }\end{array}$ & $\begin{array}{l}\text { Oelastic } \\
\text { (mbar) }\end{array}$ & $\begin{array}{l}\sigma_{n-e} \\
\text { imbar\} }\end{array}$ & $\begin{array}{l}\sigma\left(n, n^{\prime}\right) \\
\text { levels } \\
\text { (mbar) }\end{array}$ & $\begin{array}{c}\text { o(n,n') } \\
\text { continuum } \\
\text { (mbar) }\end{array}$ & $\underset{(m b a r)}{\sigma(n, 2 n)}$ & ${ }_{\left(n, x_{1}\right)^{a}}$ & $\underbrace{a}_{\left(m, x_{2}\right)^{\sigma}}$ \\
\hline 32 & 1.602 & 1988 & 1921 & 67 & - & - & - & 22 & 45 \\
\hline 33 & 1.791 & 1745 & 1647 & 98 & - & - & - & 13 & 85 \\
\hline 34 & 1.989 & 1558 & 1479 & 79 & - & - & - & 20 & 59 \\
\hline 35 & 2.198 & 1428 & 1282 & 146 & - & - & - & 36 & 110 \\
\hline 36 & 2.418 & 1409 & 1274 & 135 & - & - & - & 30 & 105 \\
\hline 37 & 2.648 & 1390 & 1234 & 156 & - & - & - & 21 & 135 \\
\hline 38 & 2.889 & 1618 & 1329 & 289 & 2 & - & - & 42 & 245 \\
\hline 39 & 3.140 & 1600 & 1237 & 363 & 4 & - & - & 39 & 325 \\
\hline 40 & 3.401 & 1723 & 1298 & 425 & 6 & - & - & +7 & 370 \\
\hline 41 & 3.673 & 1797 & 1418 & $37 s$ & 10 & - & - & 59 & $3: 0$ \\
\hline 42 & 3.955 & 2065 & 1575 & 490 & 15 & - & - & 75 & \pm 00 \\
\hline 43 & 4.248 & 1696 & 1285 & 410 & 18 & - & - & 52 & 34.0 \\
\hline 44 & 4.551 & 1218 & 844 & 374 & 24 & - & - & 50 & 300 \\
\hline 45 & 4.865 & 1275 & 920 & 355 & 31 & - & - & 49 & $2: 5$ \\
\hline 46 & 5. 189 & 1459 & $: 197$ & 262 & 44 & - & - & 48 & 170 \\
\hline 47 & 5.524 & 1382 & 1106 & 276 & 60 & - & - & 48 & 170 \\
\hline 48 & 5.869 & 1421 & 1119 & 302 & 85 & - & - & 42 & 175 \\
\hline 49 & 6.224 & 1307 & 095 & 312 & 112 & - & - & $\$ 2$ & 160 \\
\hline 53 & 6.590 & 1208 & 893 & 315 & 138 & - & - & 37 & 140 \\
\hline 51 & 6.967 & 1428 & 1054 & 374 & 155 & - & - & 34 & 175 \\
\hline 52 & 7.354 & 1437 & 1043 & 394 & 180 & - & - & 34 & 180 \\
\hline 53 & 7.751 & 1375 & 959 & 416 & 181 & - & - & 35 & 200 \\
\hline 54 & 8.i 59 & 1220 & 802 & 418 & 182 & - & - & 36 & 200 \\
\hline 55 & B.57i & 1278 & 884 & 394 & 182 & 25 & - & 36 & 150 \\
\hline 56 & 9.006 & 1282 & 878 & 404 & 183 & 45 & - & 36 & 140 \\
\hline 57 & 9.445 & 1363 & 943 & 420 & 183 & 70 & - & 37 & 130 \\
\hline 58 & 9.894 & 1437 & 1002 & 435 & 183 & 96 & - & 36 & 120 \\
\hline 39 & 10.35 & 1417 & 968 & 449 & 183 & 321 & - & 35 & 110 \\
\hline 60 & 10.83 & 1402 & 940 & 462 & 182 & 149 & - & $3 i$ & 100 \\
\hline 61 & 11.31 & 1408 & э77 & 491 & 180 & 184 & - & 27 & 100 \\
\hline 62 & 11.80 & 1542 & 982 & 560 & 180 & 249 & - & 26 & 105 \\
\hline 63 & 12.56 & $151 \mathrm{~F}$ & 961 & 555 & 170 & 280 & 2 & 23 & 80 \\
\hline 64 & 13.33 & 1526 & 983 & 543 & 142 & 300 & 4 & 22 & 75 \\
\hline 65 & 13.87 & 1550 & 989 & 561 & 138 & 330 & 6 & 22 & 65 \\
\hline 66 & $\begin{array}{l}14.41 \\
14.60\end{array}$ & 1550 & 980 & 570 & 135 & 345 & 8 & 22 & 60 \\
\hline
\end{tabular}

\footnotetext{
${ }^{a} x_{1}$ and $x_{2}$ stand for single- and double-charged particles, respectiveiv.
} 
Table 4. Neutron Library $B$ for nitrogen.

\begin{tabular}{|c|c|c|c|c|c|c|c|c|c|}
\hline Group & $\begin{array}{c}E_{\text {initial }} \\
\text { (MeV) }\end{array}$ & $\begin{array}{l}\sigma_{\text {total }} \\
\text { (mbar) }\end{array}$ & $\begin{array}{c}\text { Oelastic } \\
\text { (mba-) }\end{array}$ & $\begin{array}{c}\sigma_{\text {n-e }} \\
\text { (mbar) }\end{array}$ & $\begin{array}{l}\sigma\left(n, n^{\prime}\right) \\
\text { levels } \\
\text { (mibar) }\end{array}$ & $\begin{array}{c}\sigma\left(n, n^{\prime}\right) \\
\text { continu }{ }^{(m b a r)} \\
\text { (mbar }\end{array}$ & $\begin{array}{l}\sigma_{(\mathrm{n}, 2 n)} \\
(\mathrm{mbar})\end{array}$ & $\underset{(\mathrm{mbar})}{\sigma_{\left(n, x_{1}\right)^{2}}}$ & $\left.{ }^{0}{ }_{\left(n_{1} x_{2}\right)}\right)^{(m b a r)}$ \\
\hline 32 & 1.602 & 1988 & 1921 & 67 & - & - & - & 22 & 45 \\
\hline 33 & 1.791 & 1745 & 1647 & 98 & - & - & - & 13 & 85 \\
\hline 34 & 1.989 & 1559 & $14: 9$ & 78 & - & - & - & 20 & 59 \\
\hline 35 & 2.198 & 1428 & 1282 & 146 & - & - & - & 36 & 110 \\
\hline 36 & 2.418 & 1409 & 1274 & 135 & - & - & - & 30 & 105 \\
\hline 37 & 2.548 & 1390 & 1234 & 156 & - & - & - & 21 & 135 \\
\hline 39 & 2.889 & 1618 & 1328 & 290 & 3 & - & - & 42 & 245 \\
\hline 39 & 3.140 & 1600 & 1231 & 369 & 10 & - & - & 34 & 325 \\
\hline 40 & 3.401 & 1723 & 1286 & 437 & 20 & - & - & 47 & 370 \\
\hline 41 & 3.673 & 1797 & $\$ 392$ & $\leq 05$ & 36 & - & - & 59 & 310 \\
\hline 42 & 3.955 & 2065 & 1540 & 525 & 50 & - & - & 75 & 400 \\
\hline 43 & 4.248 & 1696 & 1239 & 457 & 65 & - & - & 52 & 340 \\
\hline 44 & 4.551 & 1218 & 798 & 420 & 70 & - & - & 50 & 300 \\
\hline 45 & 4.865 & 1275 & 863 & 412 & 88 & - & - & 42 & 275 \\
\hline 46 & 5.189 & 1459 & 1125 & 334 & 116 & - & - & 48 & 170 \\
\hline 47 & 5.524 & 1382 & 1020 & 362 & 146 & - & - & 46 & $: 70$ \\
\hline 48 & 5.869 & 1421 & 1026 & 395 & 178 & - & - & 42 & 175 \\
\hline 49 & 6.224 & 1307 & 884 & 423 & 220 & - & - & 40 & 180 \\
\hline 50 & 6.590 & 1189 & 750 & 439 & 240 & - & - & 37 & 152 \\
\hline 51 & 6.967 & 1428 & 870 & 558 & 272 & - & - & 34 & $25^{\circ}$ \\
\hline 52 & 7.354 & 1437 & 910 & 527 & 242 & - & - & 34 & $25 t$ \\
\hline 53 & 7.751 & 1375 & 997 & 478 & 240 & - & - & 35 & 203 \\
\hline 54 & 8.159 & 1220 & 782 & 438 & 240 & - & - & 36 & 162 \\
\hline 55 & 8.577 & 1278 & 750 & 528 & 240 & 25 & - & 36 & 307 \\
\hline 50์ & 9.006 & 1282 & 792 & 490 & 230 & 45 & - & 36 & 179 \\
\hline 57 & 9.445 & 1363 & 836 & 527 & 220 & 70 & - & 37 & 200 \\
\hline 58 & 9.894 & 1437 & 858 & 579 & 210 & 96 & - & 36 & 237 \\
\hline 59 & 10.35 & 1417 & 831 & 586 & 200 & 127 & - & 35 & 224 \\
\hline 60 & 10.83 & 1402 & 787 & 615 & 200 & 166 & - & 31 & 218 \\
\hline 61 & 11.31 & 1468 & 820 & 648 & 180 & 204 & - & 27 & 237 \\
\hline 62 & 11.80 & 1542 & 880 & 660 & 177 & 254 & 1 & 26 & 202 \\
\hline 63 & 12.56 & 1516 & 920 & 596 & 170 & 280 & 2 & 23 & 121 \\
\hline 64 & $13 \overline{3} .33$ & 1525 & 950 & 575 & 142 & 300 & 4 & 22 & 97 \\
\hline 65 & 13.87 & 1550 & 955 & 595 & 138 & 330 & 6 & 22 & 99 \\
\hline 66 & $\begin{array}{l}14.4 i \\
14.60\end{array}$ & 1550 & 960 & 590 & 135 & 355 & 8 & 22 & 70 \\
\hline
\end{tabular}

\footnotetext{
${ }^{a} x_{1}$ and $x_{2}$ stand for single- and double-charge particles, respectively.
} 


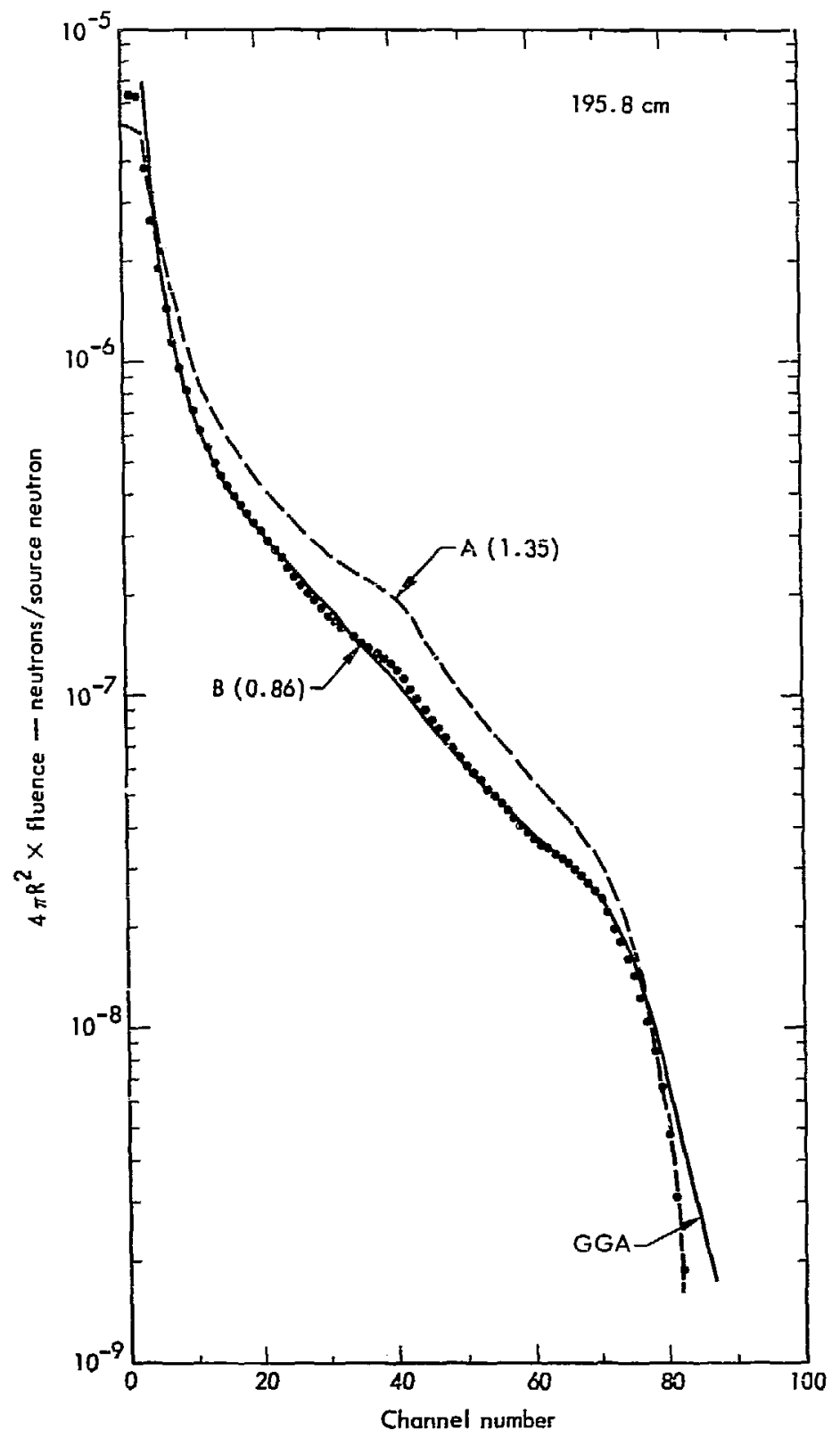

Fig. 4. Comparison between the GGA measurements of the neutron fluence in liquid nitrogen at a distance of $195.8 \mathrm{~cm}$ from the $14-\mathrm{MeV}$ soirce and SORS calculations carried out with Libraries A and $B$. The numbers in parenthesis are the normalization factors. 
Each of these two nitrogen libraries were used with the cross sections for oxygen given in Table 1 to calculate ${ }^{4}$ the neutron transport in air. Figure 5, which was taken from Ref. 4, shows the neutron doses as a function of distance calculated with SORS; a 14-MeV point neutron source is assumed in an infinite air medium with a constant density of $1.29 \mathrm{mg} / \mathrm{cm}^{3}$. Straker's ${ }^{2}$ calculation is also shown and is in closer agreement with the one carried out with Library B. Overall, the differences

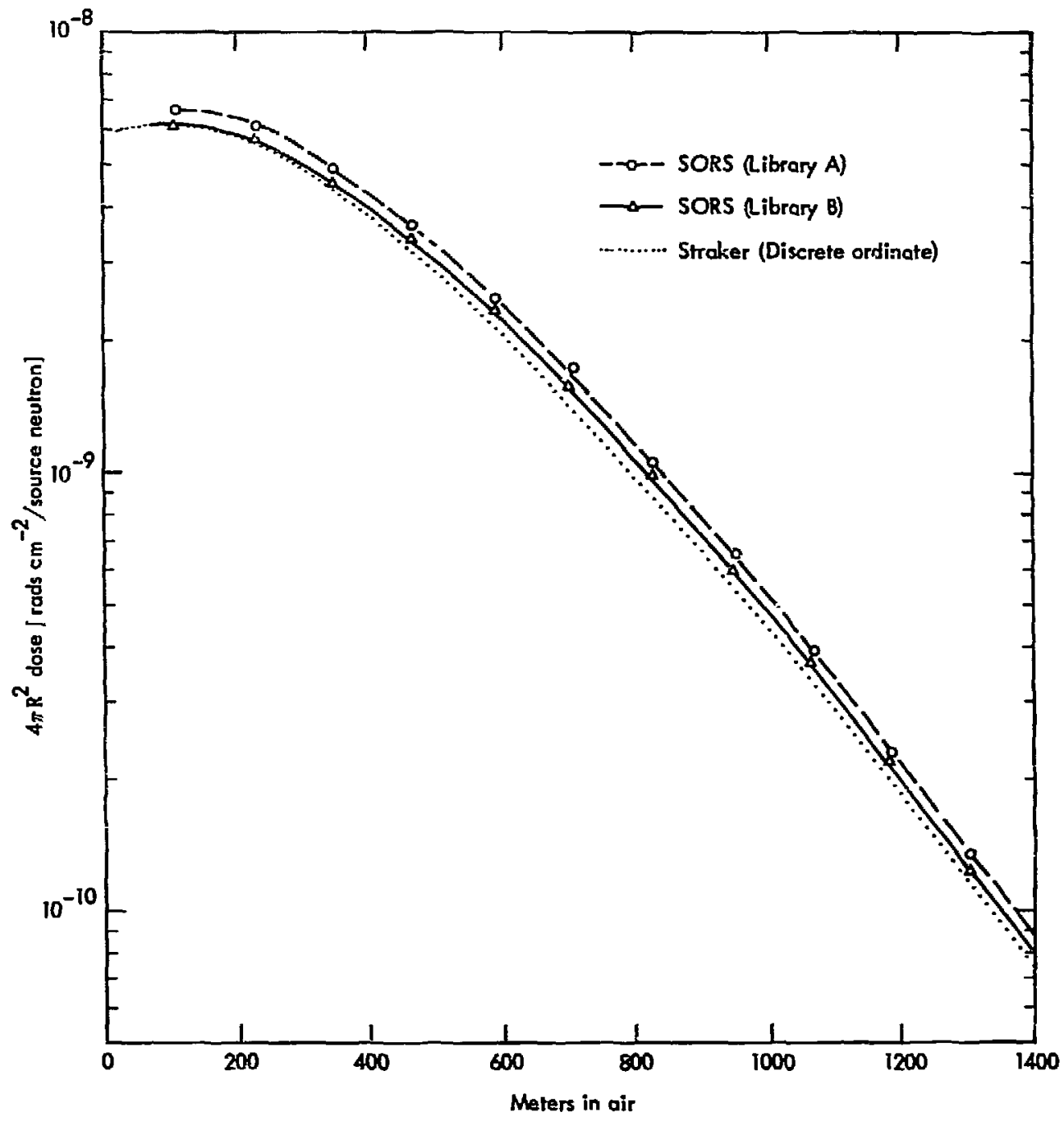

Fig. 5. Comparison of the neutron doses as a function of distance from a 14-MeV neutron source is an infinite air medium with constant density $1.29 \mathrm{mg} / \mathrm{cm}^{3}$, as predicted by SORS using Libraries $A$ and $B$ and by Straker's 2 calculations using the Discrete Ordinate Method. 
between the calculations using Libraries $\mathrm{A}$ and $B$ are no larger than $20 \%$.

The neutron nuences in $\mathrm{air}^{+}$and in nitrogen ${ }^{11}$ for different neutron energies were also calc lated with Libraries $A$ and $B$ as a function of distance from the 14-MeV neutron source. In both media the differences between the predictions of $A$ and $B$ are larger for neutron energies between 3 and $11 \mathrm{MEV}$. Fuences calculated with Library A were higher by as much as $30 \%$ for air and as much as $50 \%$ for nitrogen at the larger distances.

The preceding discussion summarizes the results of calculations already pubIished in the literature for Libraries $A$ and $B$. Calculations using Library 9 gave generally better agreement with the measurements 4,12 and with the dose and fluence calculations carried out by Straker. ${ }^{2,3}$

The low-energy measurements ${ }^{5}$ for nitrogen indicated that better agreement could be achieved with the calculations if the $\left(n, n^{\prime}\right)$ cross sections to the contiruum were lowered. A similar conclusion could be obtained by observing that the calculations are higher between 1.5 and $3 \mathrm{MeV}$ in the high-energy pulse sphere measurements (see Fig. 3).

Harris et al. ${ }^{14}$ reported a large $(n, \alpha)$ cross section in nitrogen at $14 \mathrm{MeV}$ by measuring the $\gamma$-ray yield. They observed high-energy $\gamma$ rays, which they attributed to the ${ }^{14} \mathrm{~N}(\mathrm{n}, \alpha)^{11} \mathrm{~B}$ reaction populating a 5.0-1MeV state and a pair of states at 6.7 MeV in ${ }^{11} \mathrm{~B}$, all of which subsequently decayed to the ground state. They ${ }^{14}$ estimated that the $(n, \alpha)$ cross sections to these levels could account for as much as 200 mbar and thereby remove a major part of the discrepancy observed in the nitrogen nonelastic cross sections. ${ }^{10}$
The experimental evidence ${ }^{4,5}$ for a lower (n, n') cross section to the continuum, the possibility of a larger $(n, \alpha)$ cross section, and the impracticability of having two neutron cross section libraries for nitrogen led to the formulation of Library C. Library C has the following features: (a) the total cross sections are the revised values of Foster and Glascow (July 1969); (b) the elastic cross sections are closer to those in Library $B$; (c) the $\left(n, n^{\prime}\right)$ cross sections to the continuum were decreased as much as $30 \%$ at $14 \mathrm{MeV}$; and $(d)$ the $(n, \alpha)$ cross sections were increased accordingly so that the sum of the partial cross sections would reproduce the total cross sections.

Table $\mathbf{5}$ shows the cross sections used in Library $C$ between 1.6 - and $14.6-\mathrm{MeV}$ neutron energies, and Table 6 gives the probability distribution for the $\left(n, n^{\prime}\right)$ cross section to the discrete levels. This distribution among the five levels in nitrogen at $3.95,5.10,5.75,7.07$, and $7.95 \mathrm{MeV}$ is the same as that used in Libraries $A$ 2ad B.

SORS calculations with this library for $0.58,1.06$, and $3 \mathrm{mfp}$ of liquid nitrogen are shown in Fig. 6. Also plotted in this figure are the calculations performed earlier ${ }^{4}$ with Library $B$. The predictions of these two calculations, SORS $B$ and SORS C, are very close. However, as expected, Library $\mathrm{C}$ yields a much better fit to the neutron spectrum below 3-MeV neutron energy.

The low energy neutron spectra ${ }^{5}$ (below I MeV) were also calculated using Library C, and Fig. 7 shows a comparison with the measurements. This calculation was performed by representing the level density of the nucleus by an exponential 
Table 5. Neutron Library $\mathbf{C}$ for aitrogen.

\begin{tabular}{|c|c|c|c|c|c|c|c|c|c|c|}
\hline Group & $\begin{array}{l}E_{\text {initial }} \\
\text { (MeV) }\end{array}$ & $\begin{array}{c}\mathrm{E}_{\mathrm{av}} \\
(\mathrm{MeV})\end{array}$ & $\begin{array}{l}\sigma_{\text {total }} \\
\text { (mbar) }\end{array}$ & $\begin{array}{c}\sigma_{\text {elastic }} \\
\text { (mbar) }\end{array}$ & $\underset{\text { (mbar) }}{\sigma_{n-e}}$ & $\begin{array}{l}\text { o(n,a') } \\
\text { level: } \\
\text { (mbar) }\end{array}$ & $\begin{array}{c}\sigma\left(n, n^{\prime}\right) \\
\text { continuum } \\
\text { (mbar) }\end{array}$ & $\begin{array}{c}\sigma_{(n, 2 n)} \\
\text { (mbar) }\end{array}$ & $\sigma_{\left(\mathrm{n}, \mathrm{x}_{1}\right)^{2}}^{\mathrm{a}}$ & ${ }_{(\mathrm{mbar})}^{\sigma_{\left(n, x_{2}\right)^{a}}}$ \\
\hline $\begin{array}{l}32 \\
33 \\
34 \\
35 \\
36\end{array}$ & $\begin{array}{l}1.602 \\
1.791 \\
1.989 \\
2.198 \\
2.418\end{array}$ & $\begin{array}{l}1.696 \\
1.890 \\
2.094 \\
2.308 \\
2.533\end{array}$ & $\begin{array}{l}2096 \\
1745 \\
1558 \\
1428 \\
1409\end{array}$ & $\begin{array}{l}2027 \\
1647 \\
1479 \\
1282 \\
1274\end{array}$ & $\begin{array}{r}69 \\
98 \\
79 \\
146 \\
135\end{array}$ & $\begin{array}{l}z \\
z \\
z\end{array}$ & $\begin{array}{l}z \\
z \\
z\end{array}$ & $\begin{array}{l}E \\
E \\
-\end{array}$ & $\begin{array}{l}23 \\
13 \\
20 \\
36 \\
30\end{array}$ & $\begin{array}{r}46 \\
85 \\
59 \\
110 \\
105\end{array}$ \\
\hline $\begin{array}{l}37 \\
38 \\
30 \\
40 \\
41\end{array}$ & $\begin{array}{l}2.648 \\
2.889 \\
3.140 \\
3.181 \\
3.673\end{array}$ & $\begin{array}{l}2.768 \\
3.014 \\
3.270 \\
3.537 \\
3.814\end{array}$ & $\begin{array}{l}1390 \\
1598 \\
1607 \\
1706 \\
1787\end{array}$ & $\begin{array}{l}1234 \\
1325 \\
1260 \\
1316 \\
1419\end{array}$ & $\begin{array}{l}156 \\
273 \\
347 \\
390 \\
368\end{array}$ & $\begin{array}{r}- \\
1 \\
3 \\
5 \\
7\end{array}$ & $\begin{array}{l}\bar{Z} \\
\bar{E}\end{array}$ & $\begin{array}{l}\bar{z} \\
\bar{z}\end{array}$ & $\begin{array}{l}21 \\
42 \\
34 \\
45 \\
59\end{array}$ & $\begin{array}{l}135 \\
230 \\
310 \\
340 \\
302\end{array}$ \\
\hline $\begin{array}{l}42 \\
43 \\
44 \\
45 \\
46\end{array}$ & $\begin{array}{l}3.955 \\
4.248 \\
4.551 \\
4.865 \\
5.189\end{array}$ & $\begin{array}{l}4.102 \\
4.400 \\
4.708 \\
5.027 \\
5.356\end{array}$ & $\begin{array}{l}2075 \\
1752 \\
1258 \\
1256 \\
1467\end{array}$ & $\begin{array}{r}1620 \\
1355 \\
918 \\
932 \\
1211\end{array}$ & $\begin{array}{l}455 \\
397 \\
340 \\
324 \\
256\end{array}$ & $\begin{array}{l}10 \\
25 \\
30 \\
40 \\
65\end{array}$ & $\begin{array}{l}= \\
\bar{Z} \\
-\end{array}$ & $\begin{array}{l}z \\
z \\
-\end{array}$ & $\begin{array}{l}75 \\
52 \\
50 \\
49 \\
46\end{array}$ & $\begin{array}{l}370 \\
320 \\
260 \\
235 \\
145\end{array}$ \\
\hline $\begin{array}{l}47 \\
48 \\
49 \\
50 \\
51\end{array}$ & $\begin{array}{l}5.524 \\
5.869 \\
6.224 \\
6.590 \\
6.967\end{array}$ & $\begin{array}{l}5.696 \\
6.046 \\
6.407 \\
6.778 \\
7.160\end{array}$ & $\begin{array}{l}1386 \\
1422 \\
1314 \\
1207 \\
1384\end{array}$ & $\begin{array}{r}1100 \\
1096 \\
984 \\
775 \\
827\end{array}$ & $\begin{array}{l}286 \\
326 \\
330 \\
432 \\
557\end{array}$ & $\begin{array}{r}85 \\
110 \\
130 \\
180 \\
225\end{array}$ & $\begin{array}{l}\bar{z} \\
z\end{array}$ & $\begin{array}{l}\bar{z} \\
\overline{-}\end{array}$ & $\begin{array}{l}46 \\
50 \\
40 \\
70 \\
80\end{array}$ & $\begin{array}{l}155 \\
166 \\
160 \\
182 \\
252\end{array}$ \\
\hline $\begin{array}{l}\mathbf{5 2} \\
\mathbf{5 3} \\
\mathbf{5 4} \\
\mathbf{5 5} \\
\mathbf{5 6}\end{array}$ & $\begin{array}{l}7.354 \\
7.751 \\
8.159 \\
8.577 \\
9.006\end{array}$ & $\begin{array}{l}7.552 \\
7.955 \\
8.368 \\
8.792 \\
9.226\end{array}$ & $\begin{array}{l}1440 \\
1380 \\
1230 \\
1268 \\
1299\end{array}$ & $\begin{array}{l}855 \\
845 \\
720 \\
683 \\
706\end{array}$ & $\begin{array}{l}\mathbf{5 8 5} \\
\mathbf{5 3 5} \\
\mathbf{5 1 0} \\
\mathbf{5 8 5} \\
\mathbf{5 9 1}\end{array}$ & $\begin{array}{l}240 \\
230 \\
230 \\
240 \\
240\end{array}$ & $\begin{array}{r}z \\
5 \\
15\end{array}$ & $\begin{array}{l}\bar{z} \\
\overline{ }\end{array}$ & $\begin{array}{l}85 \\
85 \\
70 \\
80 \\
76\end{array}$ & $\begin{array}{l}260 \\
220 \\
210 \\
260 \\
260\end{array}$ \\
\hline $\begin{array}{l}\mathbf{5 7} \\
\mathbf{5 8} \\
59 \\
\mathbf{6 0} \\
\mathbf{6 1}\end{array}$ & $\begin{array}{c}9.445 \\
9.894 \\
10.35 \\
10.83 \\
11.31\end{array}$ & $\begin{array}{c}9.670 \\
10.12 \\
10.59 \\
11.07 \\
11.55\end{array}$ & $\begin{array}{l}1356 \\
1420 \\
1379 \\
1360 \\
1437\end{array}$ & $\begin{array}{l}770 \\
830 \\
780 \\
780 \\
820\end{array}$ & $\begin{array}{l}\mathbf{5 8 6} \\
\mathbf{5 9 0} \\
\mathbf{5 9 9} \\
\mathbf{5 8 0} \\
\mathbf{6 1 7}\end{array}$ & $\begin{array}{l}220 \\
220 \\
210 \\
199 \\
184\end{array}$ & $\begin{array}{r}36 \\
46 \\
80 \\
100 \\
130\end{array}$ & $\begin{array}{l}\bar{z} \\
\overline{-}\end{array}$ & $\begin{array}{l}70 \\
64 \\
65 \\
40 \\
56\end{array}$ & $\begin{array}{l}260 \\
260 \\
244 \\
241 \\
247\end{array}$ \\
\hline $\begin{array}{l}62 \\
63 \\
64 \\
65 \\
66\end{array}$ & $\begin{array}{l}11.80 \\
12.56 \\
13.33 \\
13.87 \\
14.41\end{array}$ & $\begin{array}{l}12.18 \\
12.94 \\
13.60 \\
14.14 \\
14.50\end{array}$ & $\begin{array}{l}1532 \\
1566 \\
1547 \\
1558 \\
1550\end{array}$ & $\begin{array}{l}892 \\
920 \\
952 \\
955 \\
955\end{array}$ & $\begin{array}{l}650 \\
646 \\
595 \\
603 \\
595\end{array}$ & $\begin{array}{l}177 \\
170 \\
142 \\
138 \\
135\end{array}$ & $\begin{array}{l}170 \\
210 \\
240 \\
260 \\
260\end{array}$ & $\begin{array}{l}1 \\
2 \\
4 \\
6 \\
8\end{array}$ & $\begin{array}{l}56 \\
43 \\
22 \\
22 \\
22\end{array}$ & $\begin{array}{l}246 \\
221 \\
187 \\
177 \\
170\end{array}$ \\
\hline
\end{tabular}

${ }^{a} x_{1}$ and $x_{2}$ stand for single- and double-charged particles.

Table 6. Probability distribution of the $\left(n, n^{\prime}\right)$ as a function of energy (E Division).

\begin{tabular}{cccccc}
\hline \multirow{2}{*}{$\begin{array}{c}\text { Eab } \\
\text { (MfeV) }\end{array}$} & \multicolumn{6}{c}{ Excited levels for } & \multicolumn{3}{c}{$\begin{array}{c}\text { nitrogen included in SORS } \\
\text { (IfeV) }\end{array}$} \\
\cline { 2 - 6 } & 3.95 & 5.10 & 5.75 & 7.07 & 7.95 \\
\hline 4.0 & 1.0 & - & - & - & - \\
6.25 & 0.90 & 0.10 & - & - & - \\
7.0 & 0.604 & 0.244 & 0.152 & - & - \\
8.0 & 0.373 & 0.245 & 0.336 & 0.046 & - \\
10.0 & 0.300 & 0.205 & 0.310 & 0.127 & 0.058 \\
12.0 & 0.265 & 0.190 & 0.310 & 0.157 & 0.078 \\
14.1 & 0.254 & 0.173 & 0.309 & 0.178 & 0.086 \\
\hline
\end{tabular}

function where the nuclear temperature, $\theta$, was a parameter. Agreement with the measurements is good from $1 \mathrm{MeV}$ down to $1 \mathrm{eV}$ neutron energy. The difference between the calculations carried out at temperatures of 1.25 and $1.54 \mathrm{MeV}$ is within the experimental accuracy. Similar calculations ${ }^{5}$ were carried out with SORS C to predict the low-energy measurements of GGA. ${ }^{12}$ Figure 8 compares GGA measurements with SORS calculations for neutron fluence as a finction of mean free paths for 14-MeV neutrons in liquid nitrogen. The calcuiations were performed for two nuclear temperatures: $\theta=0.98$ and 1.54 MeV. Agreement with the measurements is fair. The higher temperature gives slightly better agreement at $9.8 \mathrm{mfp}$.

Some of the high-energy neutron spectra measurements from GGA ${ }^{12}$ have 

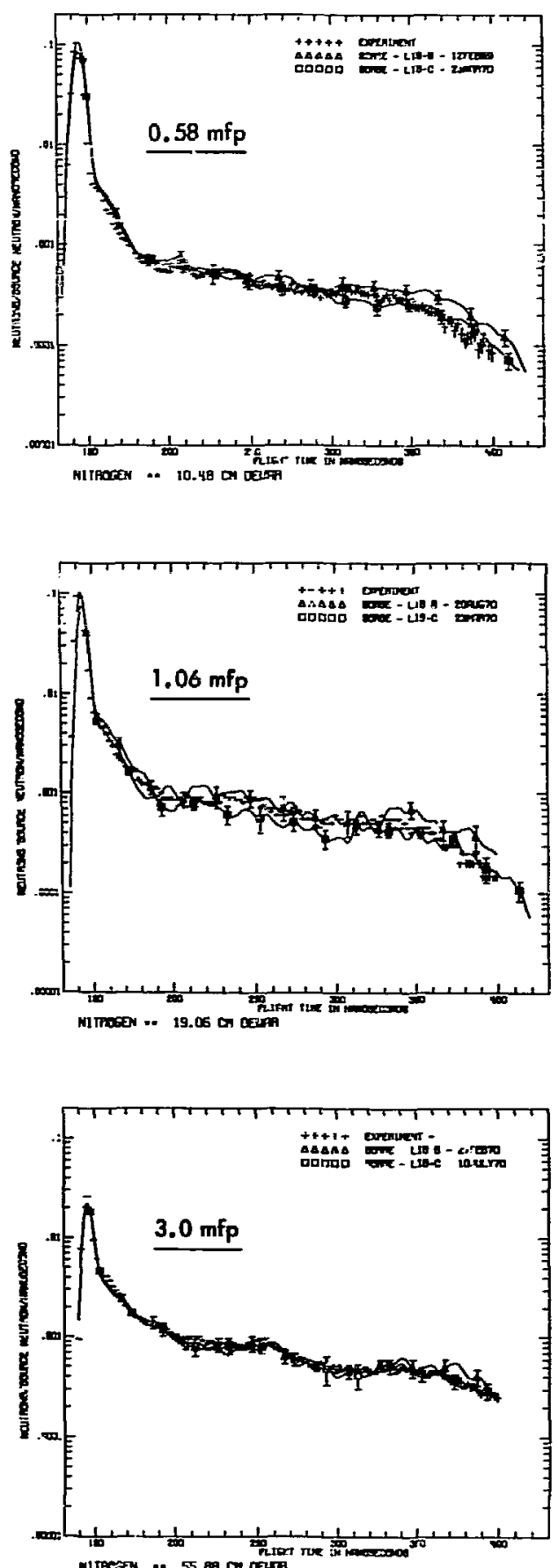

been calculated using Library $C .^{15}$ The calculated fluence of neutrons at about $10 \mathrm{mfp}$ in liquid nitrogen is given in Table 7 for Libraries $A, B$, and $C$. The $v a l u e s$ predicted $w$ ith $C$ are closer to those obtained with $B$ at the inchor energies and somewhat in between the predictions of $A$ and $B$ for the lower energies.

Having tested the neutron cross sections of Library $C$ by observing the good agreement between calculation

Table 7. The calculated fuence of neutrons from a point $(d, t)$ source ia an infinite medium of liquid nitrogen with neutron Libraries $A, B$, and $C$ for $a$ distance of $182.8 \mathrm{~cm}$. $E_{\max }$ $=15.81 \mathrm{MeV}$. Fluence is given in $4 \pi r^{2} \phi(r)$ neutrons/source neutron.

\begin{tabular}{ccccc}
\hline Group & $\begin{array}{c}\mathrm{E}_{\text {mir }} \\
\text { (Mfe })\end{array}$ & $\begin{array}{c}\mathrm{A} \\
\left(\times 10^{-3}\right)\end{array}$ & $\begin{array}{c}\mathrm{B} \\
\left(\times 10^{-3}\right)\end{array}$ & $\begin{array}{c}\mathrm{C} \\
\times 10^{-3}\end{array}$ \\
\hline 52 & 0.136 & 18.7 & 17.5 & 15.0 \\
53 & 0.261 & 14.5 & 14.8 & 12.3 \\
54 & $\left.0.42^{\prime}\right)$ & 14.2 & 11.1 & 12.8 \\
55 & 0.658 & 12.3 & 11.6 & 11.1 \\
56 & 0.8 .89 & 7.86 & 7.10 & 6.78 \\
57 & 1.18 & 8.30 & 6.00 & 6.73 \\
58 & 1.72 & 6.44 & 4.61 & 6.70 \\
59 & 2.55 & 5.08 & 3.21 & 3.72 \\
60 & 3.55 & 3.52 & 2.50 & 3.08 \\
61 & 4.73 & 3.62 & 1.89 & 3.44 \\
62 & 6.07 & 3.82 & 1.72 & 2.03 \\
63 & 7.57 & 3.31 & 1.36 & 3.01 \\
64 & 9.24 & 3.27 & 2.00 & 1.78 \\
65 & 11.1 & 4.06 & 1.96 & 1.97 \\
66 & 13.1 & 3.07 & 2.88 & 2.24 \\
\hline
\end{tabular}

Fig. 6. Comparison between the neasured neutron spectra from 0.58, 1.06 , and $3.0 \mathrm{mfp}$ of liquic nitrogen and SORS calculations carried out with neutron Libraries $B$ and $C$ given in Tables 4 and 5. 


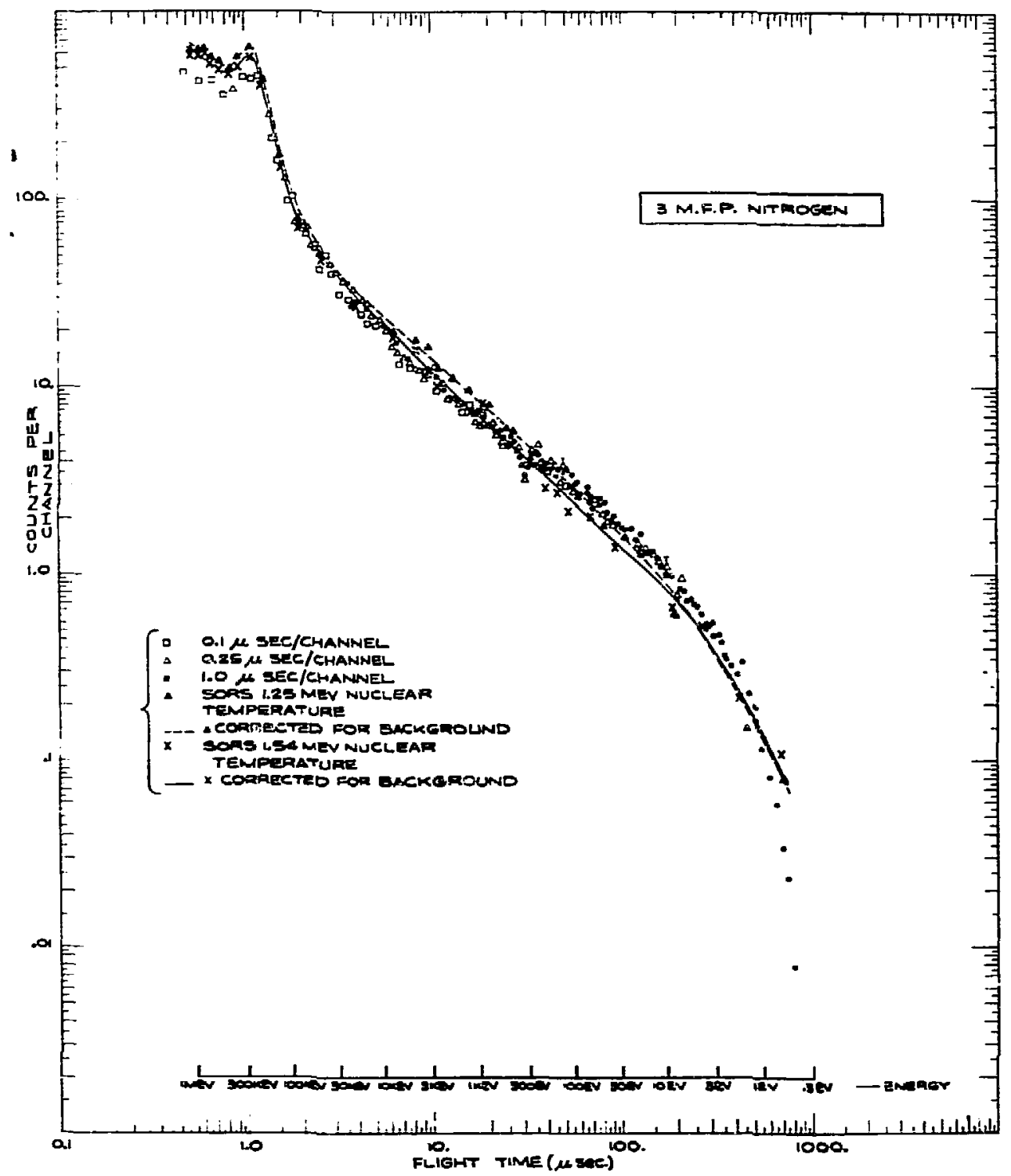

Fig. 7. Comparison between the measured spectrum below 1- MeV neutron energy from $3.0 \mathrm{mfp}$ of liquid nitrogen and SORS calculations carried out with Library C (Table 5) for two nuclear temperatures of 1.25 and $1.54 \mathrm{MeV}$. 
$50.8 \mathrm{~cm}$

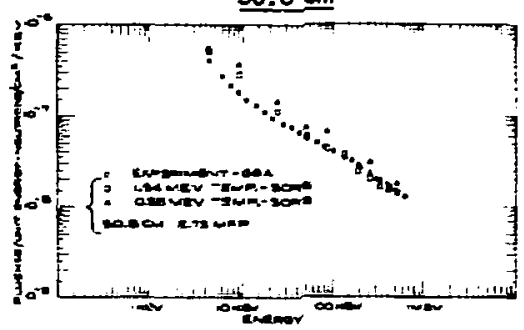

$121.9 \mathrm{~cm}$

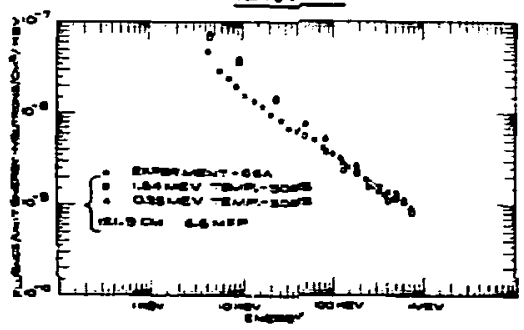

$152.4 \mathrm{~cm}$

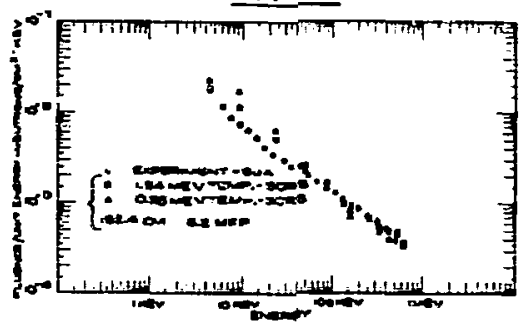

$183 \mathrm{~cm}$

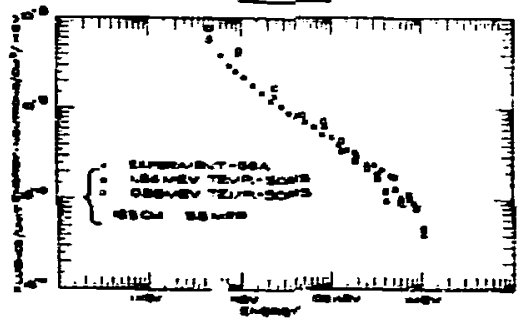

Fig. 8. Comparison between the GGA measurements of the neutron fuences in liquid nitrogen at distances of $50.8,121.9,152.4$, and $183 \mathrm{~cm}$ from the $14-\mathrm{MeV}$ source and SORS calculations carried out with Library $C$ for nuclear temperatures of 0.98 and $1.54 \mathrm{MeV}$. and measurements for $1 / 2$ to $10 \mathrm{mfp}$ of liquid nitrogen between $10 \mathrm{keV}$ and 14 MeV, it was interesting to recalculate the air transport problem using Library $C$.

SORS calculations for air were carried out with the same assumptions that had been made previously, except that the deusity of air was assumed to be $1.11 \mathrm{mg} / \mathrm{cm}^{3}$ instead of $1.29 \mathrm{mg} / \mathrm{cm}^{3}$. This change enabled us to compare our results directly with some recent calculations carried out by Straker. 16 Figure 9 shows the SORS predictions rising Library $\mathrm{C}$ for nitrogen ana the oxygen library shown in Tables 1 and 2. The neutron fluences were calculated as a function of neutron energy at distances of 400 to $1500 \mathrm{~m}$ from a $14-\mathrm{MeV}$ neutron source in an infinite homogeneous air medium. Also shown in the figure are Straker's calculations ${ }^{16}$ for the two distances. At $400 \mathrm{~m}$ the shapes are very similar, although SORS give systematically lower values for the fluences. It is felt that our calculations are to be preferred, since $40 \mathrm{sh}$ of air is comparable to $3 \mathrm{mfp}$ and Litrary $\mathrm{C}$ reproduces the low- and high-energy neutron spectra for $3 \mathrm{mfp}$ of liquid nitrogen quite well. At $1500 \mathrm{~m}$ the calculated fluences are identical up to $10 \mathrm{MeV}$. Beyond this energy. SORS predictions are higher by a factor of 2 at $13 \mathrm{MeV}$ and by a factor of 4 at $14 \mathrm{MeV}$.

The calculated total neutron fluences as a function of distance in an infinite air medium from a 14-MeV $(d, t)$ neutron source are shown in Fig. 10. Straker and Gritzner's ${ }^{16}$ calculations are in excellent agreement with the SORS C predictions. 
NEUTRON TRANSPORT TO 400 METERS IN INFINITE HOMOGENEOUS AIR

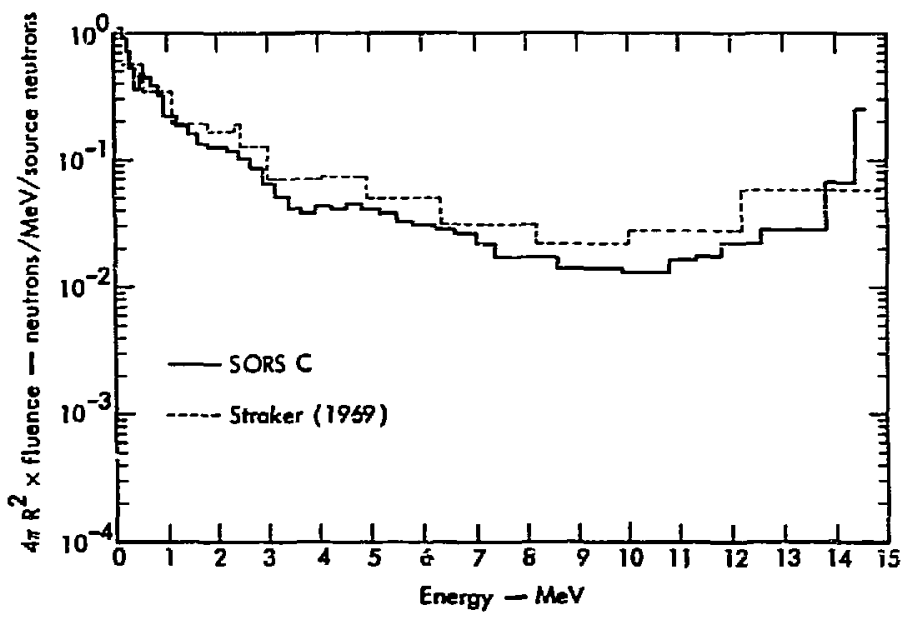

NEUTRON TRANSPORT TO 1500 METERS IN INFINITE HOMOGENEOUS AIR

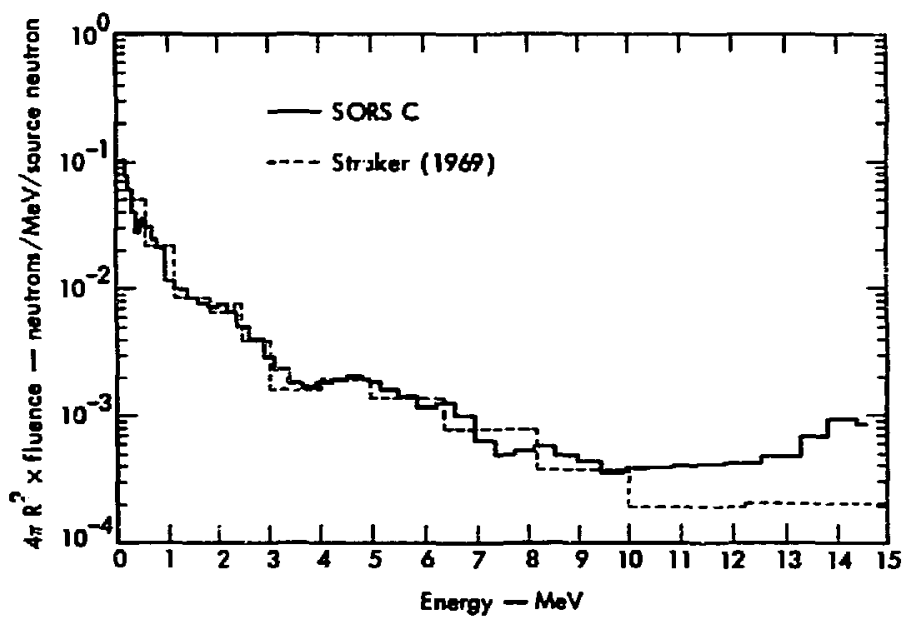

Fig. 9. Comparison of the calculated neutron fluences at 400 and $1500 \mathrm{~m}$ from a $14-\mathrm{MeV}$ source in an infinite air medium with constant density $1.11 \mathrm{mg} / \mathrm{cm}^{3}$ as predicted by SORS using Library $C$ and by Straker's calculations. 16 


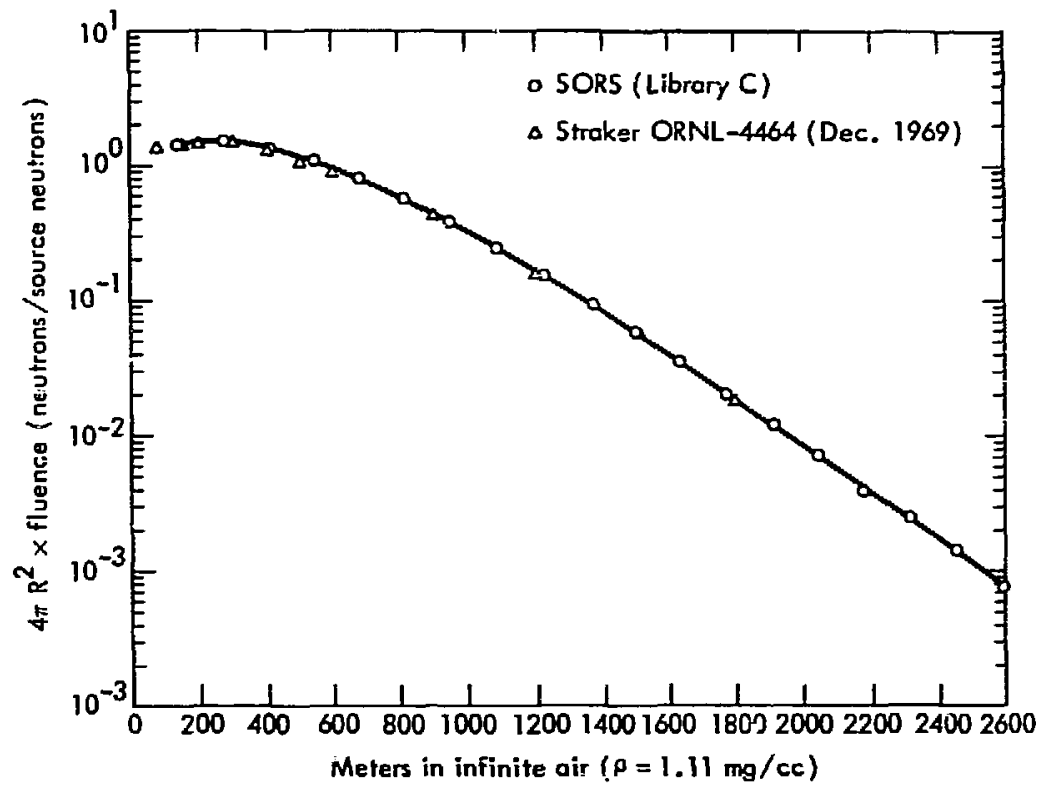

Fig. 10. Comparison of the neutron doses as a iunction of distance from a $14-\mathrm{MeV}$ source in an infinite air medium with constant density $1.11 \mathrm{mg} / \mathrm{cm}^{3}$ as predictef by SORS using Library $C$ and by Straker's calculations.

\section{Comparison of the Calculations Using Library C for Nitrogen With Other Evaluations}

SORS calculations for neutron transport in liquid nitrogen for a $14-\mathrm{MeV}$ source were carried out with the public SORSND library. 6 Using the program CLYDE, the LRL library was processed into the format of the libraries used in the calculations reported in this paper. Table 8 shows the cross sections for $\mathrm{ni}$ trogen between $1.6-$ and $14.6-\mathrm{MeV}$ neutrons that exist in the LRL library, and Table 6 gives the probability distribution for the $\left(n, n^{\prime}\right)$ cross section among the inelastic levels in nitrogen as a function of neutron energy. A comparison of the SORS calculations with this library and library $C$ is shown in Fig. 11 for the integral neutron spectrum above $1.6 \mathrm{MeV}$ for $0.58,1.06$, and $3.0 \mathrm{mfp}$ of liquid nitrogen. Although the statistical errors in the calculations are somewhat large, especially for the 3-mfp case, the predictions of SORS with the LRL library are systematically and significantly higher than the measurements and the predictions using Library $C$. This effect is attributed to the larger $\left(n, n^{\prime}\right)$ cross sections that exist in the public SORS Library. 16

Finally, a similar comparison was carried out using the nitrogen cross sections evaluated by P. G. Young. ${ }^{17}$ Here, 
Table 8. LRL neutron library for nitrogen.

\begin{tabular}{|c|c|c|c|c|c|c|c|c|c|c|}
\hline Group & $\begin{array}{c}E_{\text {initia! }} \\
\text { (MeV) }\end{array}$ & $\begin{array}{c}\mathrm{E}_{\mathrm{av}} \\
(\mathrm{MeV})\end{array}$ & $\begin{array}{l}o_{\text {total }} \\
\text { (mbar) }\end{array}$ & $\begin{array}{c}\sigma_{\text {elastic }} \\
\text { (mbar) }\end{array}$ & $\begin{array}{l}\sigma_{n-e} \\
\text { (mbar) }\end{array}$ & $\begin{array}{l}\sigma_{\left(n, n^{\prime}\right)} \\
\text { levels } \\
\text { (mbar) }\end{array}$ & $\begin{array}{c}\sigma\left(n, n^{1}\right) \\
\text { cantinuum } \\
\text { (mbar) }\end{array}$ & $\begin{array}{c}\sigma_{(n, 2 n)} \\
(m b a r)\end{array}$ & ${ }_{\left.\left(m, x_{1}\right)^{a r}\right)}^{a}$ & $\underset{(\mathrm{mbar})}{\sigma_{\left(n, x_{2}\right)}}$ \\
\hline $\begin{array}{l}32 \\
33 \\
34 \\
35 \\
36\end{array}$ & $\begin{array}{l}1.602 \\
1.791 \\
1.989 \\
2.198 \\
2.418\end{array}$ & $\begin{array}{l}1.696 \\
1.890 \\
2.094 \\
2.308 \\
2.533\end{array}$ & $\begin{array}{l}2095 \\
1816 \\
1628 \\
1586 \\
1390\end{array}$ & $\begin{array}{l}2027 \\
1721 \\
1549 \\
1451 \\
1263\end{array}$ & $\begin{array}{r}68 \\
95 \\
79 \\
135 \\
127\end{array}$ & $\begin{array}{l}E \\
z\end{array}$ & $\begin{array}{l}\bar{z} \\
\bar{z}\end{array}$ & $\bar{z}$ & $\begin{array}{l}23 \\
13 \\
20 \\
36 \\
29\end{array}$ & $\begin{array}{l}45 \\
82 \\
59 \\
99 \\
98\end{array}$ \\
\hline $\begin{array}{l}37 \\
38 \\
39 \\
40 \\
41\end{array}$ & $\begin{array}{l}2.648 \\
2.889 \\
3.140 \\
3.401 \\
3.673\end{array}$ & $\begin{array}{l}2.768 \\
3.014 \\
3.270 \\
3.537 \\
3.814\end{array}$ & $\begin{array}{l}1398 \\
1673 \\
1667 \\
1735 \\
1809\end{array}$ & $\begin{array}{l}1172 \\
1400 \\
1322 \\
1344 \\
1444\end{array}$ & $\begin{array}{l}226 \\
273 \\
345 \\
391 \\
365\end{array}$ & $\begin{array}{r}- \\
2 \\
3 \\
5\end{array}$ & $\begin{array}{l}\bar{z} \\
\overline{-}\end{array}$ & $\begin{array}{l}= \\
\bar{Z} \\
\end{array}$ & $\begin{array}{r}103 \\
42 \\
34 \\
45 \\
59\end{array}$ & $\begin{array}{l}123 \\
231 \\
309 \\
343 \\
301\end{array}$ \\
\hline $\begin{array}{l}42 \\
43 \\
44 \\
45 \\
46\end{array}$ & $\begin{array}{l}3.955 \\
4.248 \\
4.551 \\
4.865 \\
5.189\end{array}$ & $\begin{array}{l}4.102 \\
4.400 \\
4.708 \\
5.027 \\
5.356\end{array}$ & $\begin{array}{l}2117 \\
1139 \\
1236 \\
1322 \\
1454\end{array}$ & $\begin{array}{r}1664 \\
1383 \\
941 \\
1052 \\
1265\end{array}$ & $\begin{array}{l}453 \\
356 \\
295 \\
270 \\
189\end{array}$ & $\begin{array}{r}6 \\
8 \\
9 \\
12 \\
24\end{array}$ & $\begin{array}{l}\overline{ } \\
=\end{array}$ & $\underline{z}$ & $\begin{array}{l}74 \\
52 \\
30 \\
24 \\
24\end{array}$ & $\begin{array}{l}373 \\
296 \\
256 \\
234 \\
141\end{array}$ \\
\hline $\begin{array}{l}47 \\
48 \\
49 \\
50 \\
51\end{array}$ & $\begin{array}{l}5.524 \\
5.859 \\
6.224 \\
6.590 \\
6.967\end{array}$ & $\begin{array}{l}5.696 \\
6.046 \\
6.407 \\
6.778 \\
7.160\end{array}$ & $\begin{array}{l}1376 \\
1469 \\
1342 \\
1469 \\
1487\end{array}$ & $\begin{array}{l}1153 \\
1211 \\
1067 \\
1200 \\
1156\end{array}$ & $\begin{array}{l}223 \\
258 \\
275 \\
264 \\
331\end{array}$ & $\begin{array}{r}44 \\
68 \\
94 \\
120 \\
141\end{array}$ & $\begin{array}{l}\bar{Z} \\
\overline{-}\end{array}$ & $\begin{array}{l}= \\
z\end{array}$ & $\begin{array}{l}24 \\
24 \\
23 \\
23 \\
23\end{array}$ & $\begin{array}{l}155 \\
166 \\
158 \\
121 \\
167\end{array}$ \\
\hline $\begin{array}{l}52 \\
53 \\
54 \\
55 \\
56\end{array}$ & $\begin{array}{l}7.354 \\
7.751 \\
8.159 \\
8.577 \\
9.006\end{array}$ & $\begin{array}{l}7.552 \\
7.955 \\
8.368 \\
8.792 \\
9.226\end{array}$ & $\begin{array}{l}1410 \\
1392 \\
1259 \\
1304 \\
1361\end{array}$ & $\begin{array}{r}1066 \\
1003 \\
924 \\
992 \\
1024\end{array}$ & $\begin{array}{l}\mathbf{3 4 4} \\
\mathbf{3 8 9} \\
\mathbf{3 3 5} \\
\mathbf{3 1 2} \\
\mathbf{3 3 7}\end{array}$ & $\begin{array}{l}154 \\
168 \\
181 \\
194 \\
223\end{array}$ & $\begin{array}{l}= \\
= \\
=\end{array}$ & $\begin{array}{l}z \\
z \\
=\end{array}$ & $\begin{array}{l}22 \\
22 \\
21 \\
21 \\
21\end{array}$ & $\begin{array}{r}168 \\
199 \\
133 \\
57 \\
93\end{array}$ \\
\hline $\begin{array}{l}\mathbf{5 7} \\
\mathbf{5 8} \\
\mathbf{5 9} \\
\mathbf{6 0} \\
\mathbf{6 1}\end{array}$ & $\begin{array}{c}9.445 \\
9.894 \\
10.35 \\
10.83 \\
11.31\end{array}$ & $\begin{array}{c}9.670 \\
10.12 \\
10.50 \\
11.07 \\
11.55\end{array}$ & $\begin{array}{l}1440 \\
1454 \\
1393 \\
1432 \\
1499\end{array}$ & $\begin{array}{r}1064 \\
1038 \\
936 \\
931 \\
956\end{array}$ & $\begin{array}{l}376 \\
416 \\
457 \\
50 ! \\
543\end{array}$ & $\begin{array}{l}200 \\
200 \\
200 \\
200 \\
200\end{array}$ & $\begin{array}{r}67 \\
112 \\
159 \\
207 \\
255\end{array}$ & $\begin{array}{l}= \\
=\end{array}$ & $\begin{array}{l}20 \\
20 \\
19 \\
19 \\
18\end{array}$ & $\begin{array}{l}89 \\
84 \\
79 \\
75 \\
70\end{array}$ \\
\hline $\begin{array}{l}62 \\
63 \\
64 \\
65 \\
66\end{array}$ & $\begin{array}{l}11.80 \\
12.56 \\
13.33 \\
13.87 \\
14.41\end{array}$ & $\begin{array}{l}12.18 \\
12.94 \\
13.60 \\
14.14 \\
14.50\end{array}$ & $\begin{array}{l}1551 \\
1523 \\
1520 \\
1594 \\
1527\end{array}$ & $\begin{array}{l}951 \\
859 \\
889 \\
893 \\
923\end{array}$ & $\begin{array}{l}600 \\
664 \\
731 \\
697 \\
704\end{array}$ & $\begin{array}{l}200 \\
200 \\
200 \\
200 \\
200\end{array}$ & $\begin{array}{l}318 \\
389 \\
417 \\
433 \\
443\end{array}$ & $\begin{array}{l}\overline{2} \\
3 \\
4 \\
5\end{array}$ & $\begin{array}{l}18 \\
17 \\
16 \\
15 \\
15\end{array}$ & $\begin{array}{l}64 \\
56 \\
95 \\
45 \\
41\end{array}$ \\
\hline
\end{tabular}

${ }^{a} x_{1}$ and $x_{2}$ stand for single- and double-charged particles.

again, it was necessary to put these cross sections ino the proper format through

CLYDE. A tabulation of these cross sections is given in Table 9. Furthermore, since Young's evaluation had ten inelastic levels for nitrogen while our format only permits five levels, the $\left(n, n^{\prime}\right)$ cross sections to the ten levels were regrouped into five levels at $3.95,5.10,5.75,7.07$, and 7.97 MeV; their probability distributions as a function of neutron energy are given in Table 10. The comparison of SORS calculations with Young is evaluation and the C library is shown in Fig. 12. It is seen that the agreement between these two calculations for $0.58,1.06$, and $3.0 \mathrm{mfp}$ of aitrogen is excellent. This is probably due to the close agreement of the neutron elastic and inelastic cross sections at the higher neutron energies (groups 64, 65, 66). The total absorption cross sections, mainly through the $(n, p)$ and $(n, \alpha)$ channels, are identical in the two libraries. However, the $(n, p)$ cross sections in Young's library are much larger at the higher energies, which in turn results in lower $(n, a)$ cross sections than those quoted in Library C. The greatest discrepancies between these two libraries occur for neutron energies 

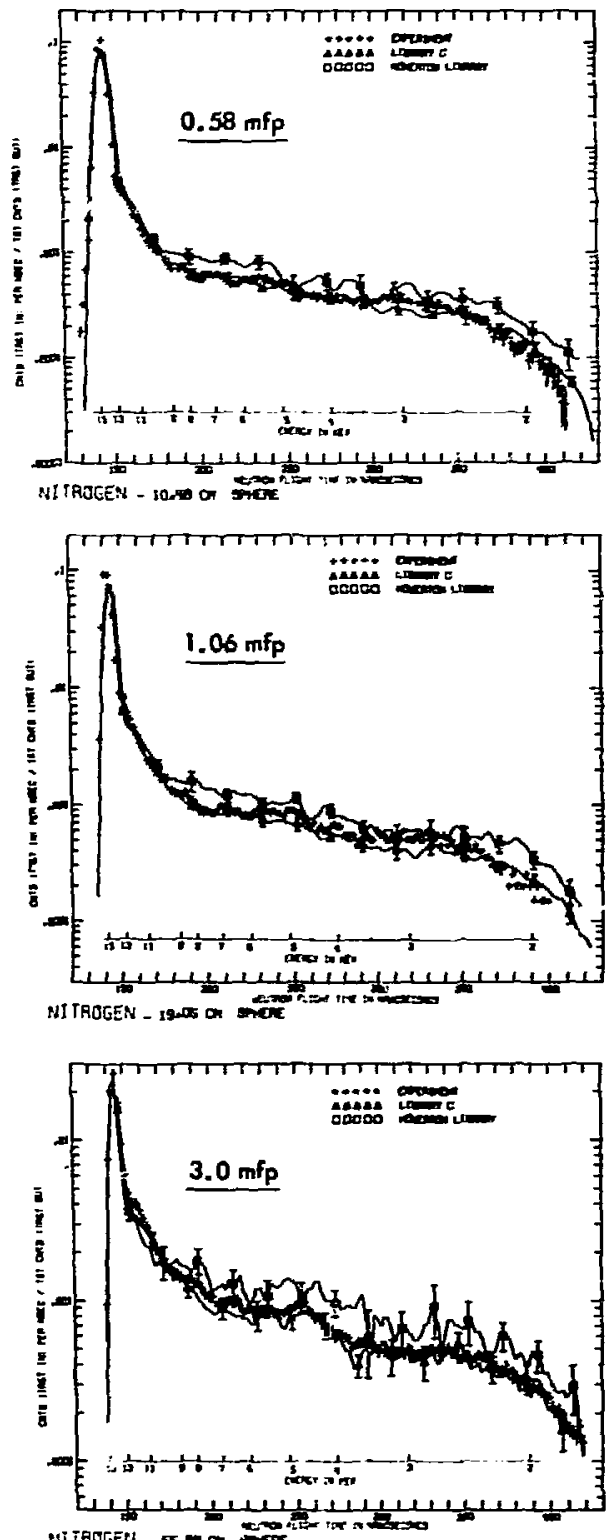

Fig. 11. Comparison between the measured neutron spectra from 0.58 , 1.06 , and $3.0 \mathrm{mfp}$ of liquid nitrogen and SORS calculations carried out with Library $C$ and the LRL Library given in Tables 5 and 9 , respectively.
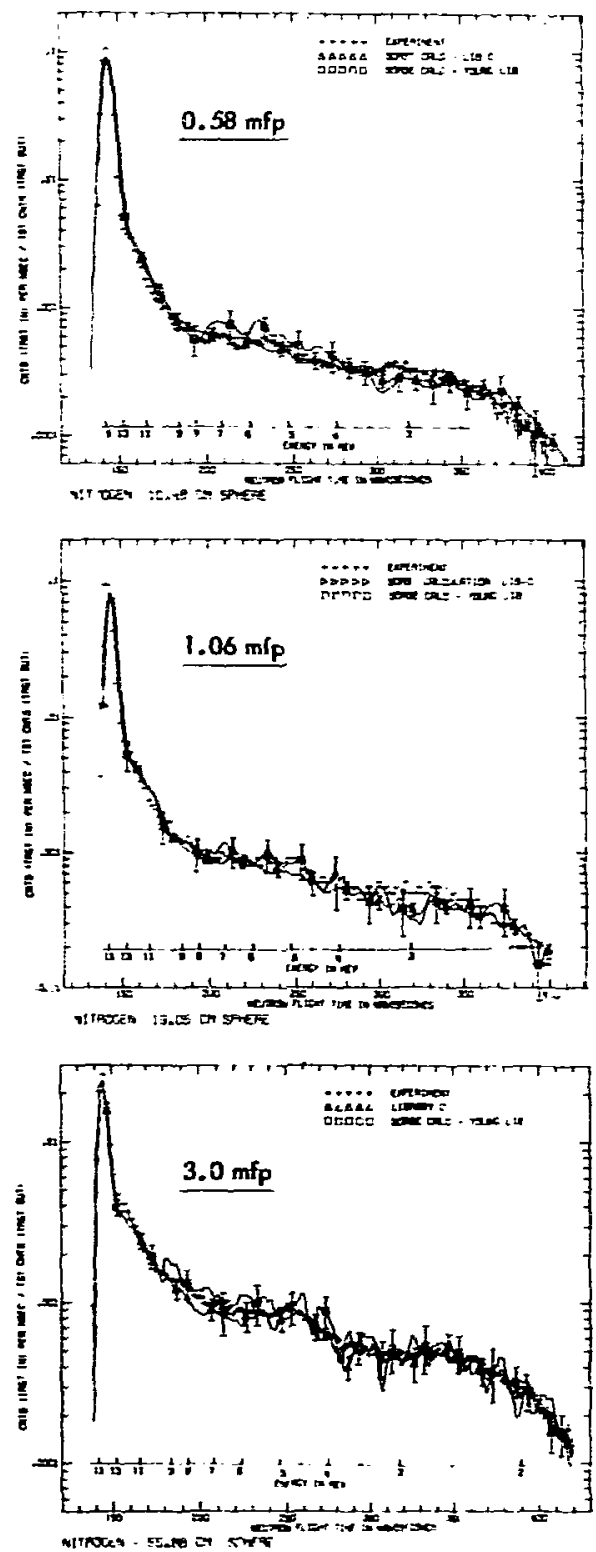

Fig- 12. Comparison between the measured spectra from $0.58,1.06$, and $3.0 \mathrm{mfp}$ of liquid nitrogen and SORS calculations carried out with Library $C$ and the Young-Foster library 17 given in Tables 5 and 10, respectively. 
Table 9. Young and Foster neutron libra.y for nitrogen.

\begin{tabular}{|c|c|c|c|c|c|c|c|c|c|c|}
\hline Group & $\underset{\text { (Ninitisl }}{E_{\text {(NeV) }}}$ & $\begin{array}{c}\mathrm{E}_{\mathrm{ay}} \\
(\mathrm{MeV})\end{array}$ & $\begin{array}{l}\sigma_{\text {total }} \\
\text { (mbar) }\end{array}$ & $\begin{array}{l}\text { a elastic } \\
\text { (mbar) }\end{array}$ & $\begin{array}{l}{ }_{\text {on-e }} \\
\text { (mbar; }\end{array}$ & $\begin{array}{l}\text { '(3,n': } \\
\text { levels } \\
\text { (mbar) }\end{array}$ & $\begin{array}{c}\sigma\left(a, u^{\prime}\right) \\
\text { coni ini.sm } \\
\text { (mbis:? }\end{array}$ & $\begin{array}{l}{ }_{\left(\mathrm{n} . \mathrm{In}^{\prime}\right)} \\
\text { (mbar) }\end{array}$ & $\begin{array}{l}\left.\sigma_{\left(n, x_{1}\right)}\right)^{n} \\
(\mathrm{E} b \mathrm{r})\end{array}$ & 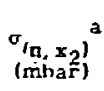 \\
\hline $\begin{array}{l}32 \\
33 \\
34 \\
35 \\
36\end{array}$ & $\begin{array}{l}1.602 \\
1.791 \\
1.989 \\
2.198 \\
2.416\end{array}$ & $\begin{array}{l}1.696 \\
1.890 \\
2.094 \\
2.308 \\
2.533\end{array}$ & $\begin{array}{l}2112 \\
176 ! \\
1559 \\
1551 \\
1461\end{array}$ & $\begin{array}{l}2025 \\
1690 \\
1452 \\
1422 \\
1304\end{array}$ & $\begin{array}{r}87 \\
71 \\
107 \\
129 \\
157\end{array}$ & $\begin{array}{l}z \\
z \\
=\end{array}$ & $\begin{array}{l}\bar{z} \\
\bar{z} \\
-\end{array}$ & $\begin{array}{l}\bar{z} \\
\overline{-}\end{array}$ & $\begin{array}{l}20 \\
11 \\
17 \\
36 \\
29\end{array}$ & $\begin{array}{r}57 \\
60 \\
90 \\
93 \\
128\end{array}$ \\
\hline $\begin{array}{l}37 \\
38 \\
39 \\
40 \\
41\end{array}$ & $\begin{array}{l}2.648 \\
2.889 \\
3.140 \\
3.401 \\
3.673\end{array}$ & $\begin{array}{l}2.758 \\
3.024 \\
3.270 \\
3.537 \\
3.814\end{array}$ & $\begin{array}{l}1494 \\
1726 \\
1673 \\
1702 \\
1850\end{array}$ & $\begin{array}{l}1159 \\
1378 \\
1294 \\
1351 \\
1409\end{array}$ & $\begin{array}{l}335 \\
348 \\
379 \\
355 \\
441\end{array}$ & $\begin{array}{l}1 \\
1 \\
2 \\
3 \\
5\end{array}$ & $\begin{array}{l}z \\
z\end{array}$ & $\begin{array}{l}z \\
z \\
-\end{array}$ & $\begin{array}{r}105 \\
39 \\
32 \\
44 \\
55\end{array}$ & $\begin{array}{l}229 \\
398 \\
345 \\
304 \\
381\end{array}$ \\
\hline $\begin{array}{l}42 \\
43 \\
44 \\
45 \\
46\end{array}$ & $\begin{array}{l}3.955 \\
4.248 \\
4.551 \\
4.865 \\
5.189\end{array}$ & $\begin{array}{l}4.102 \\
4.400 \\
4.708 \\
5.027 \\
5.356\end{array}$ & $\begin{array}{l}2085 \\
170 \leq \\
1268 \\
1191 \\
1459\end{array}$ & $\begin{array}{r}1548 \\
1378 \\
921 \\
951 \\
1231\end{array}$ & $\begin{array}{l}437 \\
346 \\
277 \\
240 \\
228\end{array}$ & $\begin{array}{r}6 \\
9 \\
17 \\
26 \\
.88\end{array}$ & $\begin{array}{l}\bar{z} \\
\overline{-}\end{array}$ & $\begin{array}{l}\bar{z} \\
\bar{z}\end{array}$ & $\begin{array}{l}75 \\
49 \\
39 \\
36 \\
36\end{array}$ & $\begin{array}{l}356 \\
228 \\
221 \\
178 \\
154\end{array}$ \\
\hline $\begin{array}{l}47 \\
48 \\
49 \\
50 \\
51\end{array}$ & $\begin{array}{l}5.524 \\
5.869 \\
6.224 \\
6.590 \\
6.967\end{array}$ & $\begin{array}{l}5.696 \\
6.045 \\
6.407 \\
6.778 \\
7.160\end{array}$ & $\begin{array}{l}1366 \\
1419 \\
1356 \\
1218 \\
1396\end{array}$ & $\begin{array}{r}1125 \\
1148 \\
1053 \\
875 \\
1010\end{array}$ & $\begin{array}{l}241 \\
271 \\
303 \\
343 \\
386\end{array}$ & $\begin{array}{r}69 \\
86 \\
121 \\
152 \\
179\end{array}$ & $\begin{array}{l}\bar{z} \\
\bar{z}\end{array}$ & $\begin{array}{l}\bar{z} \\
\bar{z}\end{array}$ & $\begin{array}{l}38 \\
43 \\
50 \\
55 \\
57\end{array}$ & $\begin{array}{l}143 \\
142 \\
132 \\
136 \\
150\end{array}$ \\
\hline $\begin{array}{l}52 \\
53 \\
54 \\
55 \\
56\end{array}$ & $\begin{array}{l}7.354 \\
7.751 \\
8.159 \\
8.577 \\
9.006\end{array}$ & $\begin{array}{l}7.552 \\
7.955 \\
8.368 \\
8.792 \\
9.226\end{array}$ & $\begin{array}{l}1484 \\
1481 \\
1242 \\
1279 \\
1274\end{array}$ & $\begin{array}{r}1067 \\
1054 \\
841 \\
905 \\
901\end{array}$ & $\begin{array}{l}417 \\
427 \\
401 \\
374 \\
373\end{array}$ & $\begin{array}{l}195 \\
201 \\
190 \\
184 \\
184\end{array}$ & $\begin{array}{r}- \\
-1 \\
2 \\
11\end{array}$ & $\begin{array}{l}= \\
= \\
=\end{array}$ & $\begin{array}{l}57 \\
54 \\
53 \\
53 \\
57\end{array}$ & $\begin{array}{l}165 \\
172 \\
157 \\
135 \\
121\end{array}$ \\
\hline $\begin{array}{l}57 \\
58 \\
59 \\
60 \\
61\end{array}$ & $\begin{array}{c}9.445 \\
9.894 \\
10.35 \\
10.83 \\
11.31\end{array}$ & $\begin{array}{c}9.670 \\
10.12 \\
10.59 \\
11.07 \\
11.55\end{array}$ & $\begin{array}{l}1323 \\
1418 \\
1407 \\
1369 \\
1426\end{array}$ & $\begin{array}{l}931 \\
994 \\
942 \\
871 \\
902\end{array}$ & $\begin{array}{l}392 \\
424 \\
165 \\
498 \\
524\end{array}$ & $\begin{array}{l}183 \\
: 83 \\
183 \\
182 \\
179\end{array}$ & $\begin{array}{r}28 \\
46 \\
70 \\
94 \\
118\end{array}$ & $\begin{array}{l}\bar{z} \\
\frac{7}{1}\end{array}$ & $\begin{array}{r}67 \\
85 \\
104 \\
117 \\
124\end{array}$ & $\begin{array}{l}114 \\
110 \\
108 \\
105 \\
107\end{array}$ \\
\hline $\begin{array}{l}62 \\
63 \\
64 \\
65 \\
66\end{array}$ & $\begin{array}{l}11.80 \\
12.56 \\
13.33 \\
13.87 \\
14.41\end{array}$ & $\begin{array}{l}12.18 \\
12.94 \\
13.60 \\
14.14 \\
14.50\end{array}$ & $\begin{array}{l}1545 \\
1583 \\
1590 \\
1593 \\
1593\end{array}$ & $\begin{array}{l}983 \\
968 \\
960 \\
960 \\
960\end{array}$ & $\begin{array}{l}562 \\
615 \\
630 \\
633 \\
633\end{array}$ & $\begin{array}{l}176 \\
173 \\
170 \\
167 \\
164\end{array}$ & $\begin{array}{l}155 \\
211 \\
232 \\
243 \\
250\end{array}$ & $\begin{array}{l}2 \\
4 \\
5 \\
6 \\
7\end{array}$ & $\begin{array}{l}130 \\
131 \\
128 \\
123 \\
118\end{array}$ & $\begin{array}{l}99 \\
96 \\
95 \\
94 \\
94\end{array}$ \\
\hline
\end{tabular}

${ }^{a} x_{1}$ and $x_{2}$ stand for single- and double-charged particles.

Table 10. Probability distribution of the $\left(n, n^{\prime}\right)$ as a function of energy (Phillip Young).

\begin{tabular}{llllll}
\hline & \multicolumn{5}{c}{$\begin{array}{c}\text { Excited leve's } \\
\text { (MeV) }\end{array}$} \\
\cline { 2 - 6 }$(\mathrm{MeV})$ & $\mathbf{3 . 9 5}$ & 5.10 & 5.75 & $\mathbf{7 . 0 7}$ & $\mathbf{7 . 9 5}$ \\
\hline 4.0 & 1.00 & & & & \\
6.25 & 0.76 & 0.24 & & & \\
7.0 & 0.565 & 0.266 & 0.169 & & \\
8.0 & 0.386 & 0.235 & 0.293 & 0.086 \\
10.0 & 0.219 & 0.117 & 0.310 & 0.173 & 0.181 \\
12.0 & 0.148 & 0.124 & 0.292 & 0.231 & 0.205 \\
14.1 & 0.127 & 0.157 & 0.280 & 0.295 & 0.141 \\
\hline
\end{tabular}

between 7 and $11 \mathrm{MeV}$. Young's elastic cross sections are higher by as much as $30 \%$ at 8.5 MeV, resulting in a lower nonelastic cross section in this energy interval. Young's cross sections between 7 and $11 \mathrm{MeV}$ are quize similar to those given in Library $A$. 


\section{Conclusions}

Comparisons of calculations with measurements have shown that nitrogen

Library $C$ for neutron cross sections between 1.6 and $14.6 \mathrm{MeV}$ is definitely preferred over Libraries $A$ and $B$ and should be used in future SORS calculations.

Furthermore, one can conclude that many features of neutron transport in nitrogen and in air from a $14-\mathrm{MeV}$ neutron source are determined primarily by the magnitude of the neutron cross sections at energies around $14 \mathrm{MeV}$. This is especially true for the calculation of neutron dose as a function of distance from the source. However, the neutron fluence as a funution of neutron energy for a given distance is more sensitive to the value of the neutron cross sections at lower energies. Calculations of the fluences using Libraries $A$ and $B$ differ between 20 and $50 \%$ in liquid nitrogen, the difference being worse at larger distances from the souzce. For air the differences are on the order of $30 \%$ or less.

It has been shown here that all the available neutron libraries for $N$, such as Libraries $A, B$, and $C$, the ENDF/B library used by Straker in his calculations, and the latest evaluation of the ENDF/B library carried out by Young and Foster at Los Alamos (LASL), ${ }^{17}$ give very $\mathrm{sim}$ ilar results when neutron transport in air is being calculated. However, it must be pointed out that the differences between these libraries could become important when one is interested in the calculation of $\gamma$-ray transport in air. For example, Young and Foster's evaluation and Library $A$, which are very similar, have higher elastic cross sections than Libraries B or C; this will be reflected in a lower proauction of $\gamma$ rays. On the other hand, if the characteristics of $\gamma$-ray transport at distances are mainly decided by the features of the high-energy neutron cross sections, then the differences between the values for the absorption channels $(n, p),(n, d)$, or $(n, \alpha)$ in the libraries also become important. Library $C$, with its large $(n, \alpha)$ cross section, will predict harder $\gamma$ rays $\left(E_{0}=6 \mathrm{MeV}\right)$ than will Young-Foster's library, where the $(n, p)$ cross section is high and the $\gamma$ rays are much softer. This discrepancy could be resolved by remeasuring the $(n, p)$ and $(n, \alpha)$ cross sections in $N$ at higher energies.

\section{Acknowledgments}

We would like to thank Dr. Eugene Goldberg for his continuous interest and encouragement in this work. 


\section{References}

1. R. L. French and M. B. Wells, Engineering Compendium on Radiation Shielding (Springer-Verlag, Inc., New York, 1968), Vol. 1, p. 350.

2. E. A. Straker, Calculations of the Transport of Neutrons from Fission and 14-MeV Point Sources in an Infinite Medium of Air, Oak Ridge National Laboratory, Rept. ORNL-T M-1547 (1966).

3. E. A. Straker, Time-Dependent Neutron and Secondary Gamma Ray Transport in Air-Over-Ground Geometry, Oak Ridge National Laboratory, Rept. ORNL-4289 (1968).

4. L. F. Hansen, J. D. Anderson, E. Goldberg, J. Kammerdiener, E. Plechaty, and C. Wong, Nucl. Sci. Engr. 40, 262 (1970).

5. P. Brown, J. D. Anderson, W. Webster, and C. Wong, in Proc. ANS Seventeenth Annual Meeting (Boston, 1970).

6. R. Howerton, Integrated System for Production of Neutronic and Photonic Calculated NAL Constants, Lawrence Radiation Laboratory, Livermore, Rept. UCRL-50400, Vol. IN (1970).

7. E. F. Plechaty and J. Kimlinger, SORS Monte Carlo Neutron-Transport Code, Lawrence Radiation Laboratory, Livermore, Rept. UCRL-50532 (1968).

8. D. G. Foster, Jr. and D. W. Glascow, private communication (Sept. 13, 1966); D. G. Foster, Jr., private communication (July 1969); D. G. Foster, Jr. and D. W. Glascow, Phys. Rev. C 3, 576 (1971).

9. R. W. Bauer, J. D. Anderson, H. F. Lutz, C. Wong, J. W. McClure and B. A. Pohl, Nucl. Phys. A93, 673 (1967).

10. J. K. Dickens and F. G. Perey, Nucl. Sci. Engr. 36, 280 (1969).

11. G. D. Sauter and P. A. Robinson, Calculations of the Transport of Neutrons from a $(d, t)$ Source Through Many Mean Free Paths in Liquid Nitrogen, Lawrence Radiation Laboratory, Livermore, Rept. UCRL-50856 (1970).

12. J. L. Pigg and J. L. Russell, Jr., Neutron Penetration Measurements Program, AEC Report GA-8485, Gulf General Atomic Incorporated (1968).

13. J, L. Russell, Jr., Measurements and Analysis of the Transport of Fast Neutrons in Liquid Nitrogen, DASA Report GA-9081, Gulf General Atomic Incorporated (1968).

14. R. J. Harris, Jr., G. M. Reynolds, W. E. Selph, and S. M. Sperling, Transactions ANS 12, 958 (1969).

15. P. A. Robinson, private communication (May 1970).

16. E. A. Straker and M. L. Gritzner, Neutron and Secondary $\gamma$-rays Transport in Infinite Homogeneous Air, Oak Ridge National Laboratory, Rept. ORNL-4464 (1969).

17. P. G. Young and D. G. Foster, Jr., private communication (May 197D). 
NOTICE

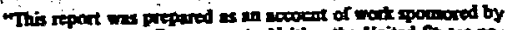

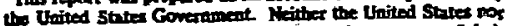

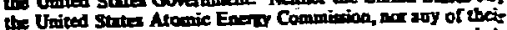

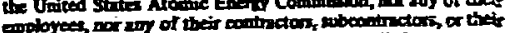

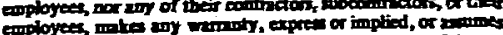

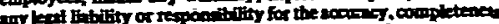

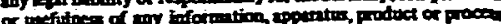

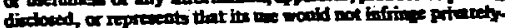
ownd rithe"

\footnotetext{
Printed in USA. Available from the National Terhnical Information Center, National Bureau of Standards,

U. S. Department of Commerce, Springfield, Virginia 22151 Price: Printed Copy \$3.00; Microfiche $\$ 0.65$.
} 